\title{
WestVirginiaUniversity
}

THE RESEARCH REPOSITORY @ WVU

Graduate Theses, Dissertations, and Problem Reports

2005

\section{Survey of athletic training clinical education: Perceptions from the field}

Alan Nasypany Jr.

West Virginia University

Follow this and additional works at: https://researchrepository.wvu.edu/etd

\section{Recommended Citation}

Nasypany, Alan Jr., "Survey of athletic training clinical education: Perceptions from the field" (2005).

Graduate Theses, Dissertations, and Problem Reports. 4179.

https://researchrepository.wvu.edu/etd/4179

This Dissertation is protected by copyright and/or related rights. It has been brought to you by the The Research Repository @ WVU with permission from the rights-holder(s). You are free to use this Dissertation in any way that is permitted by the copyright and related rights legislation that applies to your use. For other uses you must obtain permission from the rights-holder(s) directly, unless additional rights are indicated by a Creative Commons license in the record and/ or on the work itself. This Dissertation has been accepted for inclusion in WVU Graduate Theses, Dissertations, and Problem Reports collection by an authorized administrator of The Research Repository @ WVU.

For more information, please contact researchrepository@mail.wvu.edu. 
Survey of Athletic Training Clinical Education: Perceptions from the Field

Alan Nasypany Jr. M.Ed, ATC, CSCS

Dissertation submitted to the

School of Physical Education

at West Virginia University

in partial fulfillment of the requirements

for the degree of

Doctor of Education in Physical Education

Andrew Hawkins (Chair) $\mathrm{PhD}$

Helen Hazi (Cognate Advisor) PhD

Michelle Sandrey $\mathrm{PhD}$

Samuel Zizzi EdD

Mia Erickson EdD

Morgantown, WV

2005

Keywords: Athletic training, clinical education, perceptions, ACIs 


\title{
Abstract \\ Survey of Athletic Training Clinical Education: Perceptions from the Field
}

\begin{abstract}
Alan Nasypany Jr.
The purpose of this study was to identify: 1) Who are ACIs; 2) What are the perceptions of the clinical education process since the implementation of the 2001 Proficiencies, Standards, and Guidelines; 3) What factors are most and least facilitating to the clinical education process; and 4) What factors should be first addressed to improve the clinical education process. Online surveys were sent to 298 Program Directors and they were asked to distribute them to ACIs in their programs. Two weeks later, the survey was posted on the Athletic Training Education Listserve. Two hundred and twelve surveys were returned. The results indicated that 205 (97\%) of the ACIs sampled, identified this as an important topic for athletic training research the results also indicated that ACIs are generally satisfied with the implementation of the 2001

Proficiencies, Standards, and Guidelines. The ACIs that responded to the survey believed that personal factors within their control generally facilitated the clinical education process, while those institutional factors (e.g. time, documentation, etc.) facilitate less. Possibly the most important finding of this study is that although the implementation of the 2001 Proficiencies, Standards, and Guidelines was met with significant resistance from the ground level (practitioners), ACIs, currently feel reasonably satisfied with their ability to perform in the clinical education process. This is crucial in that the overall findings of this study were so positive especially when considering the top down nature of these changes to the Proficiencies, Standards, and Guidelines. Future research should examine the "less facilitating" factors and seek steps to improve these factors.
\end{abstract}


TABLE OF CONTENTS

CHAPTER1 - INTRODUCTION AND STATEMENT OF PROBLEM

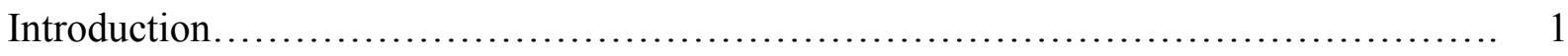

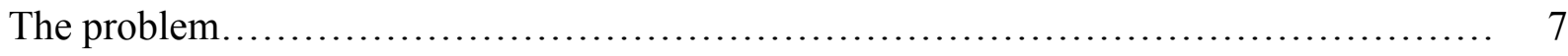

Statement of the problem.......................................................... 10

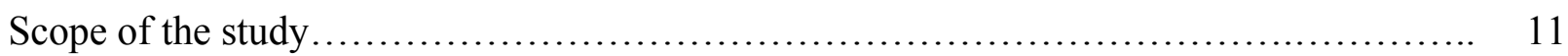

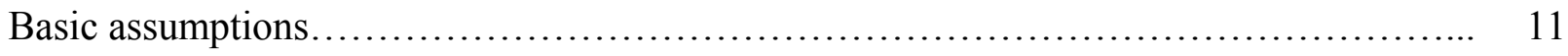

Limitations of the study ........................................................... 12

Definitions of terms................................................................. 12

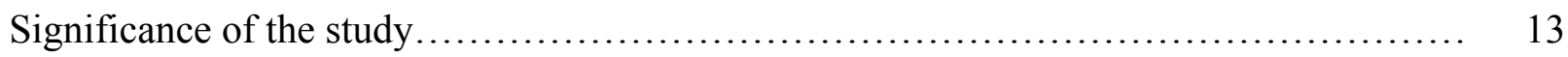

CHAPTER 2 - REVIEW OF LITERATURE......................................... 14

History of Clinical Education in Athletic training.................................. 14

Recent Trends in Allied Health and Athletic training Clinical Education................. 16

Recent Research Findings In Athletic training Clinical Education....................... 18

State of Clinical Education...................................................... 20

Factors That Affect (Facilitate or Impede) Clinical Education.......................... 21

Lack of Time.............................................................. 22

Communication Skills................................................... 22

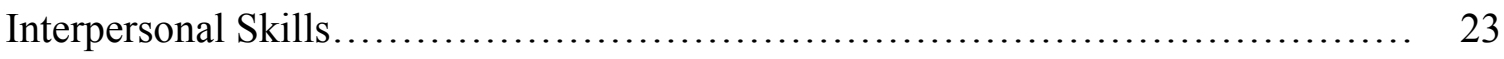

Leadership Skills............................................................ 24

Supervisory Skills..................................................... 24

Ability to Change Practice.................................................. 25

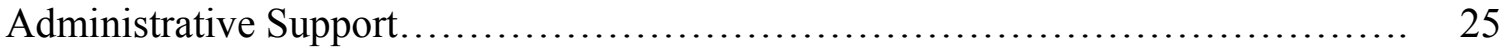




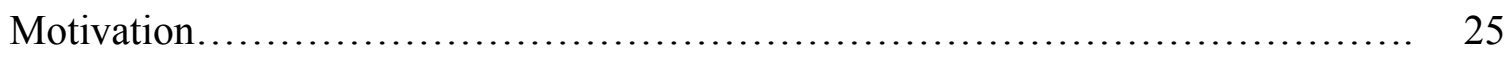

Formal Teacher Preparation and Experience.................................. 26

Student Supervision Experience............................................. 27

Evaluation and Assessment Skills......................................... 27

ACI to Student Ratio........................................................... 27

Clinical Competence..................................................... 28

Relationship with Students................................................ 28

Facilities and Adequate Space............................................. 28

Administrative Skills..................................................... 29

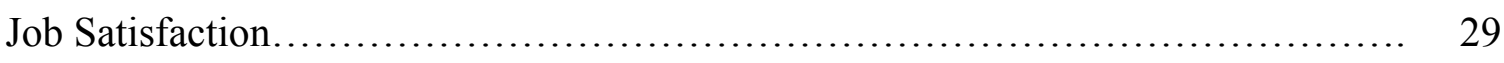

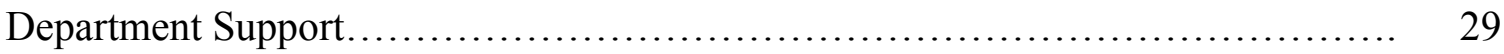

Communication With Other Faculty and Staff Within the AT Curricula............ 29

Demographic Characteristics of Athletic training Educators........................... 31

Steps For Improvement of Clinical Education....................................... 33

Improvement of Student Supervision...................................... 33

Organizational Improvements............................................. 35

Establishment of Clinical Education Faculty ................................... 36

Focus on Student Learning ............................................... 36

Collaboration Between Classroom and Clinical Instructors...................... 36

Pedagogical Improvement................................................... 37

CHAPTER 3 - METHODS 39

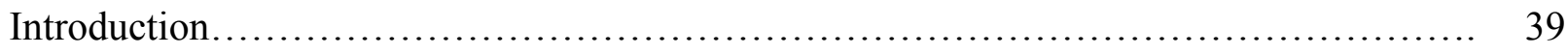

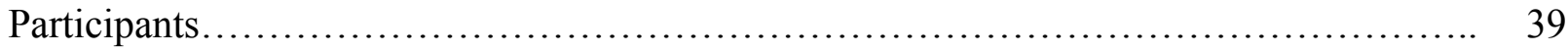


Pilot Research.................................................................. 40

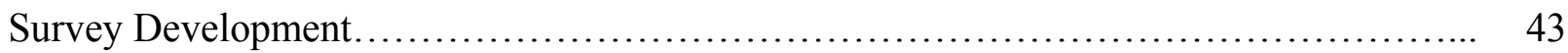

Survey Methodology Factors................................................... 47

Coverage and Sampling Error.............................................. 47

Measurement Error.......................................................... 48

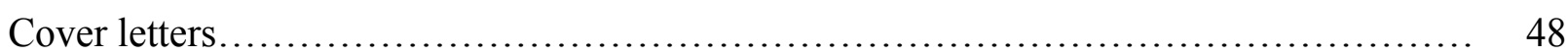

Web Survey Design................................................................... 48

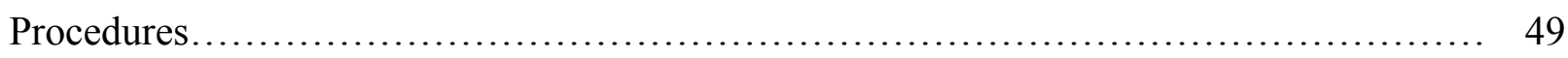

Research Questions............................................................ 51

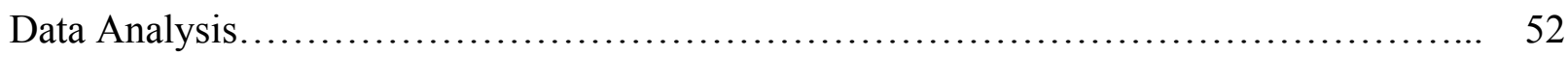

\section{CHAPTER 4- RESULTS}

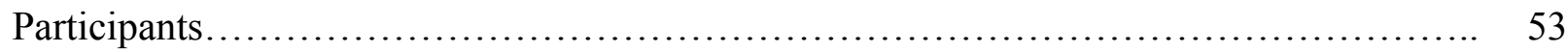

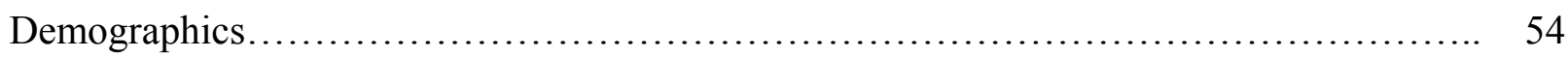

ACI Titles................................................................ 54

ACIs' Position Requirements.............................................. 55

Perceptions of the Clinical Education Process......................................... 55

Factors Perceived as Affecting the Clinical Education Process........................... 56

Facilitators.............................................................. 56

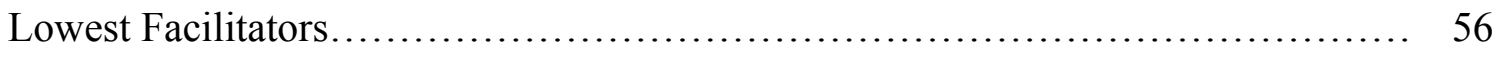

Most Important Factors to First Address ........................................... 56

$\begin{array}{ll}\text { CHAPTER 5- DISCUSSION } & 57\end{array}$

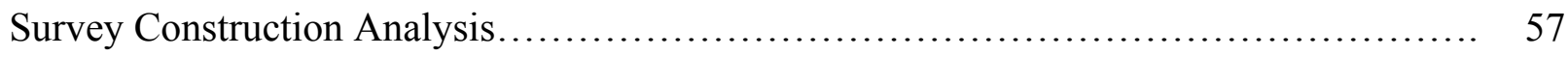

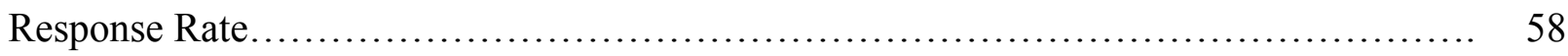


Sample Demographics...................................................... 58

Perceptions of the Athletic Training Process.......................................... 61

Factors Influencing Clinical Education.......................................... 62

Most Important to First Address................................................. 64

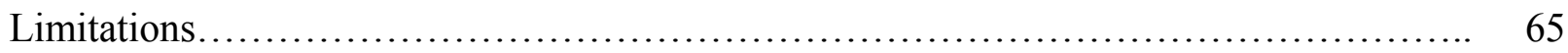

Conclusions and Notes for Practice................................................ 65

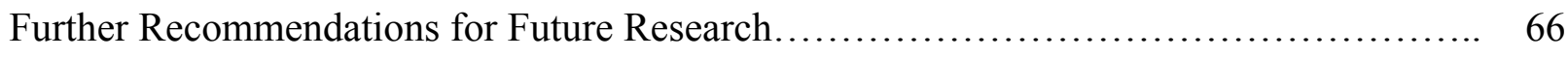

$\begin{array}{lr}\text { REFERENCES } & 68\end{array}$

$\begin{array}{ll}\text { APPENDICIES } & 74\end{array}$

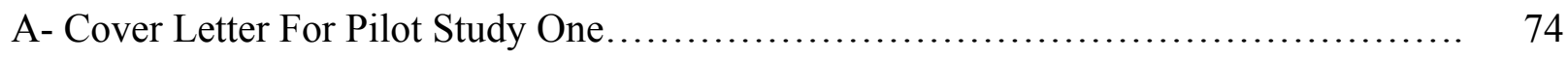

B- Cover Letter For Pilot Study Two (Participants)................................... 76

C- Cover Letter For Pilot Study Two (Program Directors)........................... 77

D- Cover Letter For Final Survey................................................... 79

E- Survey for Pilot Study One ..................................................... 81

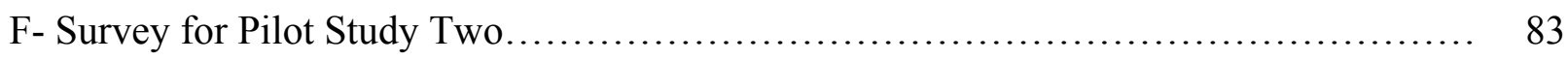

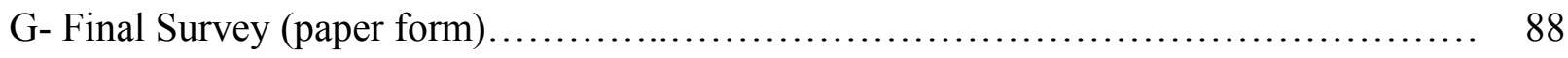

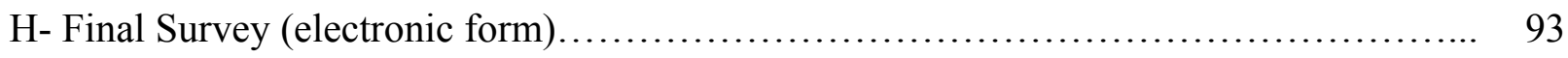

$\begin{array}{ll}\text { TABLES } & 100\end{array}$ 


\section{LIST OF TABLES}

Table 1. Demographic Characteristics of ACIs

Table 2. Other Demographic Characteristics of ACIs

Table 3. Title(s) Held By ACI's At Their Institution

Table 4. Perceptions of the Clinical Education Process since the Implementation of the 2001

Proficiencies, Standards, and Guidelines

Table 5. The Top Ten Most Facilitating Factors to the Clinical Education Process as Perceived by ACIs

Table 6. Top Ten Least Facilitating Factors in the Clinical Education Process as Perceived by ACIs

Table 7. The Ten Most Important Factors to be First Addressed, As Selected By ACIs 


\section{CHAPTER 1}

Introduction

Athletic training is a profession that has emerged from two principle fields: physical education and medicine. At its inception most athletic trainers were coaches, people concerned with the team, or people concerned with individuals on the team and their well-being. The early forms of athletic training took the form of emergency care, which included taping and bracing. As the physical educators and coaches became more involved with the general healthcare of the team expectations began to rise. The expectations that rose were consistent with the idea that the parties responsible for the healthcare of the individuals on the team should be held to similar standards as other people in the medical professions (Grace, 1999). The standards of care came directly from the medical profession, more precisely from the physicians. Athletic training emerged as an allied health profession in 1991 after more than two decades of struggle for recognition (Grace, 1999).

Traditionally there have been two routes to certification as an athletic trainer: internship and accreditation. The original was the internship route. The internship route typically required fewer academic courses and more clinical practice hours under the direct supervision of a Certified Athletic Trainer (ATC). The accredited route was typically more academically challenging, requiring more courses, but less clinical hours under the direct supervision of an ATC. Athletic training has recently made a shift from a split between internship based and accredited institutions, to a one hundred percent accredited athletic training curriculum. This change manifested itself secondary to the need for athletic training curricula to produce students with similar entry-level knowledge. Part of the reason for the change was that students from accredited institutions had a significantly higher first-time pass rate on the National Athletic 
Trainers' Association Board of Certification (NATABOC) Certification Exam than did students who graduated from an internship based program (Harrelson, \& Gallaspy, 1997). The NATABOC Certification Exam was established as a way to ensure that students who graduated from various athletic training programs all had the same minimal competence in the six basic domains of athletic training. These domains were the following: 1) risk management, 2) assessment and evaluation, 3) acute care, general medical conditions and disabilities, pathology of illness, pharmacological aspects of injury and illness, nutritional aspects of injury and illness, 4) therapeutic exercise and therapeutic modalities, 5) health care administration, professional development and responsibilities, and 6) psychosocial intervention and referral. After the third role delineation study for athletic trainers, these domains increased to twelve. The additional domains represented an increase in the scope of practice of entry-level ATCs.

Currently, the Commission on Accreditation of Allied Health Education Programs (CAAHEP) accredits athletic training educational programs. CAAHEP, in conjunction with the Joint Review Committee on Educational Programs in athletic training (JRC-AT) has produced a set of Proficiencies, Standards, and Guidelines. These Standards are the minimum Standards of quality used to accredit programs that prepare individuals to enter athletic training (Accreditation Standards: Athletic Training, 2001). The extent to which a program complies with these Standards determines its accreditation status. The Standards represent the minimum requirements to which an accredited program is held accountable. The guidelines portion of the Standards and Guidelines is there to assist the individual in interpreting the Standards.

Effective 2007, The JRC-AT will be severing its ties with CAAHEP. The primary reason for this is that athletic training as a profession has outgrown the purposes for which CAAHEP was initially needed-mainly as a widely respected accrediting body. CAAHEP accredits several 
allied health programs that are not four-year programs. Since CAAHEP accredits such a wide variety of allied health programs its standards are not always created with athletic training in mind. Therefore some degree of autonomy is lost and academic growth may be slowed. Also the break from CAAHEP was necessary because athletic training has reached, and in many cases exceeded, the functions of CAAHEP. The break allows athletic training to pursue higher accreditation professional organizations such as the Commission on Higher Education Accreditation (CHEA). It is beneficial for athletic training to pursue other accreditation organizations, and to let the JRC-AT guide the way through the process, as concerns specific to athletic training can be more efficiently addressed. Another reason for the split is that CAAHEP is producing a new Standards template, and the JRC-AT has voted against it, as it does not serve the purposes of athletic training and will not help the profession (Koehneke, 2003). The new CAAHEP Standards require extensive changes to programs and decrease required supervision, and patient safety requirements. The current plan is to apply to CHEA ( 2 year process), and the new revision of the Standards and Guidelines will fit seamlessly into the new accrediting body's system (Koehneke, 2003)

Therefore the JRC-AT is proposing changes to the 2001 Proficiencies, Standards, and Guidelines to fulfill compliance with CHEA. These changes are relatively minor and should not result in any changes that affect the issues that will be studied in the survey.

Clinical education is the part of the athletic training program where theory meets practice. Clinical experiences are designed to apply theoretic knowledge to real-life situations (Blue et al., 1998; Frisch, \& Coscarelli, 1986; Jarski, Kulig, \& Olson, 1990; Ladyshewsky, Barrie, \& Drake, 1998; Sloan, Donnely, \& Plymale, M., 1997; Slotnik, 1996; Villafuete, 1996). The purpose of the clinical education section of the athletic training curriculum is to build upon the foundations that 
have been made in the classroom, and to guide the student in incorporating these principles into theory-grounded practice. The student is guided through this process by an approved clinical instructor (ACI).

An ACI is a teacher in the clinical education portion of an accredited athletic training program who is directly responsible for evaluating and documenting that a student has successfully demonstrated minimal competency on clinical proficiencies. This is not an easy task. In 2001 the NATA updated the Standards and Guidelines for athletic training education programs (ATEPs) and required that by January, 2003 all clinical proficiencies must be evaluated by an ACI. Along with this new requirement, the NATA mandated that every ACI must re-certify every three years. This certification is attained through a six-hour course. Most institutions send an individual to become an ACI-educator. This individual will have been credentialed by the NATA to certify athletic trainers who wish to become ACIs. This is an attempt by the NATA to ensure similar basic clinical education knowledge in ACIs.

This improvement in the minimal competency of clinical instructors is a major step in the education of future athletic trainers. This improvement, while a good start, should not be the last step in the development of Standards for athletic training education. Another change that coincided with the introduction of the approved clinical instructor was the addition of the aforementioned clinical proficiencies.

Along with increasing the expectations of knowledge in entry-level students graduating from these programs, these accredited athletic training programs have made changes that have attempted to improve the quality of instruction and supervision that occurs, primarily in the clinical education setting. Students must demonstrate competence in a great number of cognitive, psychomotor, and affective competencies in twelve major subject areas (practice domains) 
throughout the course of their clinical education experience. This documentation of clinical competencies is referred to as the clinical proficiencies. These have replaced the old standard, which was an accumulation of 1800 clinical hours in the internship route, and about 800 hours in the accredited route. These numbers of required clinical hours under direct supervision differed from ATEP to ATEP, with the numbers listed above as minimums. With the move to the requirement of the clinical proficiencies there is currently no minimum hour requirement.

The old model of learning in the clinical education portion of the curriculum was primarily based on the assumption that knowledge would be imparted through an experiential socialization into the field. The experiential socialization refers to the process that commonly occurs in allied health programs, which assume that knowledge of how to practice in the clinical setting occurs from actually practicing in this setting regardless of the amount and quality of supervision. Not only is this setup not ideal for optimal student learning, with no feedback related to performance, but also it is potentially dangerous for the patient. It is not safe for a student who has not demonstrated the minimal entry-level knowledge that is required of ATCs through the passing of the certification exam, to be expected to provide similar levels of care as an ATC. The quantity model has been replaced with a quality model. The demonstration of clinical proficiencies mentioned above must take place in no less than two academic years and in no more than five academic years.

Learning in the clinical education portion of the curriculum is accomplished primarily in two settings. The first setting is the clinical academic course. The clinical academic course should include a laboratory class, an internship, a practicum, or an externship. The clinical course should identify contact hours, and be presented with traditional education guidelines such as a syllabus. The second setting in which clinical education occurs is in the field experience. In 
field experience settings, students are exposed to real-life situations such as practice, game, athletic training room, and clinic settings. Regardless of in which setting clinical education occurs, proper documentation of the clinical proficiencies must occur.

Clinical proficiencies can be assessed through an assortment of ways. For example, they may be assessed as part of a check-off sheet in the clinical laboratory, or they may be evaluated as part of the experiences that are gained in clinical placements such as the athletic training room or on the field. However, only approved clinical instructors (ACIs) can verify that minimal competence has been met through direct student supervision. The ACI must be within constant auditory and visual range of the practicing student. The ACI must not be engaged in any other activity other than direct one-on-one student supervision. Although the easiest way to grade clinical proficiencies is by using a check off sheet in the athletic training laboratory classroom, it is recommended that this form of assessment be used sparingly (Accreditation Standards: Athletic Training, 2001). It is strongly recommended that most of these competencies be graded over time and in traditional athletic trainer settings, such as the athletic training room, practice, game, and clinic settings. The learning over time model is the base for evaluation of the proficiencies.

Learning over time is the documented continuous process of skill acquisition, progression, and student reflection (Accreditation Standards: Athletic Training, 2001). Learning over time involves the demonstration of systematic progression through the cognitive, psychomotor, and affective taxonomies within different contextual environments (e.g. athletic training room, practice fields, etc.). Assessment of learning over time is built around multiple indicators and sources of evidence such as observations (student affective behaviors, interviews), performance samples (clinical skill demonstration), and tests and test-like procedures. 
Implementation of learning over time in the existing clinical proficiencies is a significant portion of ACI responsibility. It is a teaching philosophy that can take many years of practice to master. Although not proven in the athletic training setting, its efficacy has not been disputed. A major difficulty associated with the learning over time model is that along with the mastery process, every student that is assigned to an ACI will be at a different developmental level in the athletic training program. Therefore the ACI must maintain focus to appropriately challenge the student in order for the student to develop new proficiencies and also to be aware of previously documented proficiencies to ensure continuous learning over time. For example, an individual psychomotor skill, such as a Lachman's test for anterior cruciate ligament instability, may be assessed in the athletic training room laboratory. As the students develop their skills, this psychomotor skill should be demonstrated within the context of a thorough knee evaluation in the athletic training laboratory classroom. Next, proficiency should be noted in a real-life situation, possibly as a part of an actual patient evaluation situation.

As with the learning over time model, there are many difficulties with clinical education in general. Some of these perceived difficulties or barriers are individual, while others are institutional. Individual barriers may include an ACI's limited content knowledge, pedagogical knowledge, pedagogical content knowledge, or teaching desire.

From reviewing the pertinent literature it is clear that there has been an attempt in recent years to improve clinical education as a whole mostly by improving what is known about clinical education, and by the implementation of new Standards. While this is a necessary and useful approach, no one has published data on the effects of these new standards on the clinical educators. and the needs of the clinical educators regarding the improvement of clinical education. For example, most of the approved clinical instructors at West Virginia University are 
employed through the Department of Athletics. As a result, when their job descriptions are broken down, $95 \%$ of the ACI's time is allocated to practice related responsibility, and $5 \%$ of their time is allocated to clinical education. There is no way that proper documentation of clinical proficiencies can occur with or without the addition of the strongly recommended learning over time added. It stands to reason that since the ACI's clinical responsibilities have increased there should be a proportionate restructuring of the job responsibilities.

As with many new professions, there has been much time and energy invested into developing and/or advancing new content knowledge, increasing professional awareness, and researching and improving the study of teaching and learning. Many parallel fields such as nursing, physical therapy, occupational therapy, medicine, education, and teacher education may provide valuable starting points for research in athletic training education. Athletic training investigators can borrow information from parallel fields in efforts to keep pace with the older more established fields. Much of this saved time and effort can be spent improving other avenues of research.

A significant amount of information can also be learned from other fields regarding teaching and learning. Although many strategies may be different, it is hypothesized that many of these strategies are consistent across fields. There are advantages to researching and implementing already proven methods from other fields. However, it is necessary to research their applicability to the athletic training setting.

Research on education in athletic training has concentrated mainly on the students. There have been two main avenues of research in athletic training education: didactic (classroom) and clinical. Didactic teaching and clinical education share many commonalities. Research on didactic teaching in athletic training has focused on a relatively limited number of variables. 
Clinical education research has focused on both teaching and learning, and has been an active topic in athletic training in the last five years. Although classroom teaching and clinical education are fundamentally related, and the students are expected to be able to extrapolate data from one setting and apply them to the other, these two settings have been researched separately.

Although, Foster and Leslie (1992) noted that clinical instructors surveyed enjoyed teaching and being involved with the process, this may or may not hold true today. At the time of Foster's study, the clinical instructors surveyed averaged about 21 hours per week engaged in clinical education. It is the belief of this author that clinical educators spend significantly more time involved in clinical education today, since the implementation of the 2001 clinical education Standards. Insight into why they became ACIs or whether they would like to continue to be an ACI, along with the estimation of clinical education time involvement might be very important to assess. It is necessary to fully understand the phenomenon and identify problems before solutions are provided. Proper matching of solution to problem is always necessary. Most of literature relating to clinical education has been student centered, taken from a sample of convenience, or prescriptive. Of the articles that are clinical educator centered, most are prescriptive. Many of these articles describe different ways of teaching proficiencies or they suggest ways to become a better clinical educator (i.e., "how to" articles). While these prescriptive articles are important, they may not address the main concerns for clinical educators. Only after a study examines the current issues in clinical education as perceived by the major stakeholders, along with concerns and needs, can prescriptive measures be truly effective. Therefore, there is a need to determine perceptions of ACI's regarding the clinical education process as it currently stands. Also factors that are important to the clinical education process may provide useful insight to providing means of improvement of these issues. 
The Problem

\section{Statement of the Problem}

Attempts have been made in recent years to improve clinical education in athletic training. There has been a shift from a socialization approach to clinical education towards a quality and competency-based approach. Recently there has been a wealth of articles published in athletic training journals regarding clinical education. For example in September, 2002, Athletic Therapy Today produced a complete issue relating to athletic training clinical education. However, many of these articles have been prescriptive, suggesting measures to improve clinical education, by borrowing what other professional fields have learned about effective clinical education. While these are all important steps to improving clinical education, not enough is known about the the ACIs and their perceptions of the process as it stands. Furthermore, there has never been a tool developed to analyze perceptions of the clinical education process from the major stakeholders. It is as important to identify current issues regarding the implementation of quality clinical education, by analyzing a survey of ACI's perceptions, as it is to provide prescriptive measures and educational techniques to improve clinical education. Providing prescriptive measures implies that the process is completely understood and there is only the need to mend or improve what is already known. I do not believe this to be the case. It is hypothesized that a demographic description of the ACIs and identification of their perceptions of current clinical education issues, and their needs as ACIs may be the first necessary step to improving clinical education in athletic training. The main concept is to look at the Gestalt of athletic training clinical education including all individual and institutional factors.

Therefore, the purpose of this study was to better understand who are ACIs, to determine their perceptions of the current clinical education issues, to determine the important factors that 
facilitate or impede the implementation of quality clinical education, and to understand their most essential needs. This study examined both individual and institutional factors that affect the clinical education process as perceived by the practicing ACIs. This survey attempted to identify the current issues and continuing education needs, but also any changes, even institutional, as perceived by the ACI's, that may be beneficial toward improving athletic training clinical education.

Scope of the Study

This study used descriptive research techniques including a demographics sheet and a questionnaire that I have developed. The participants were the population of ACIs currently practicing in clinical education at CAAHEP accredited athletic training education programs in the United States and employed on a full-time basis by their university. There were at the time of this study approximately 298 approved programs. I determined that the results were most generalizable if all ACIs that are employed on a full-time basis in CAAHEP approved programs have the opportunity to answer the questionnaire. The survey contained four parts. Part One was comprised of questions that are designed to uncover ACI's perceptions of the clinical education process as it currently stands since the implementation of the 2001 Standards and Guidelines. Part Two of the survey was designed to rate that factors that facilitate or impede the clinical education process as perceived by the ACI's. Part Three was designed to identify five factors that will be most critical to address to facilitate an improvement of the clinical education process. Part Four included the demographics items pertaining to characteristics previously studied in the literature, and also on information on the participants that may be professionally relevant for future research.

Assumptions 
1) It was assumed that a relatively comprehensive list of factors has been determined in a pilot study.

2) It was also assumed that participants responded to this survey honestly.

3) It was assumed that the developed questionnaire was content valid to the extent that it stood a more than reasonable chance to better understand the clinical education process.

\section{Limitations}

1) This was an original survey with limited validation.

2) The researcher used a self-report questionnaire and these have potential reliability issues.

3) Another potential limitation was that it is possible that people who felt strongly about this topic were most likely to respond. It can be very detrimental to the study if only one end of the extremes (for or against) replies to the survey, therefore skewing the data.

\section{Definitions of Terms}

Approved clinical instructor (ACI) - An individual certified by the NATABOC to directly supervise athletic training students (ATSs).

Athletic Trainer Educational Programs (ATEPs)- accredited institutions from which one can earn the right sit for the NATABOC certification exam.

Clinical education- The portion of the athletic training education program that is the direct link from classroom theory to applied practice. This education must take place under the supervision of an approved member of the allied health community, but only a physician or ACI can supervise clinical proficiencies. The clinical education process can occur in a variety of 
settings, including but not limited to a classroom, laboratory, athletic event, clinic, hospital, physician office, etc.

NATABOC-National Athletic Trainers' Association Board of Certification; responsible for nationally certifying eligible athletic trainers.

CAAHEP-Commission on Accreditation of Allied Health Education Programs

\section{Significance of the Study}

This study identified: 1) demographic characteristics of ACIs; 2) perceptions of the ACIs regarding the clinical education process since the implementation of the 2001 Proficiencies, Standards, and Guidelines; 3) factors facilitating or impeding clinical educationand 4) the immediate needs of practicing clinical education ACIs

The primary significance of this study was that there have been no published data on the state of clinical education after the implementation of the 2001 Proficiencies, Standards, and Guidlelines. Athletic trainers are traditionally demonstrate a tendency of being in the lower academic ranks and generally work more hours in comparison to other university employees although this may be due to the relatively young mean age of the population (Hertel, West, Buckley, \& Denegar, 2001). For example, doctoral-educated program directors are on average less compensated than faculty of similar experiences and education (Hertel et al, 2001). According to the most recent NATA Salary Survey (2005) athletic trainers involved in the higher education setting report that they worked an average of 50-60 hours per week (NATA Salary Survey, 2005). This study helped to determine if the Standards have increased or decreased this traditional hardship. There have been few studies that have looked at the demographic characteristics of athletic training clinical instructors, and none that have studied ACIs specifically. To date there have been no studies that have looked at factors that facilitate or 
impede the clinical education process, and specifically from the perspective of the ACIs. Although many articles (few empirical studies) have been published in the athletic training literature about how to individually, professionally enhance the clinical education process, no study or article has addressed the institution as a contributing factor to the facilitation or impediment of athletic training clinical education. Finally, there has never been a published needs assessment of athletic training clinical instructors. 


\section{CHAPTER 2}

Review of the Literature

\section{Introduction}

Athletic training clinical education is a multi-faceted phenomenon in which hands-on skills are gained in a structured manner. Since athletic training clinical education takes place at the same time as patient care, it can become a very complicated process as compared with classroom education. In the classroom there is no question that the primary concern is the educational process whereas in the clinical setting, patient care and clinical education often compete for the same time and providers.

Chapter two discussed the history of clinical education in athletic training, recent trends in athletic training clinical education, recent research findings in athletic training clinical education, the current state of the clinical education process, and factors that facilitate or impede the clinical education process.

\section{History of Clinical Education in Athletic training}

Formal clinical education in athletic training began taking form in the 1970's (Delforge \& Behnke, 1999). At this time the National Athletic Trainers' Association (NATA) Professional Education Committee formalized a list of behavioral objectives that identified desired learning outcomes for athletic training students based on the 11 required courses. These courses were: 1) anatomy, 2) physiology, 3) physiology of exercise, 4) applied anatomy and kinesiology, 5) psychology, 6) first aid and safety, 7) nutrition, 8) remedial exercise, 9) personal, community, and school health, 10) basic athletic training, 11) laboratory or practical experience in athletic training to include a minimum of 600 on-the-clock hours under the direct supervision of a sponsoring NATA-certified athletic trainer (Weidner \& Henning, 2002b). Because the scope of 
the behavioral objectives was dictated by the content of the required courses these objectives did not represent a competency-based approach. For example there were many competencies that were not covered through the inclusion of the required courses. It was expected that these competencies would be taught elsewhere in the program, mainly in the clinical education portion of the program. The behavioral objectives initiated in the 1970s formed the conceptual framework of the Competencies in Athletic training developed by the Professional Education Committee in 1983 (Delforge and Behnke, 1999).

The Competencies in Athletic training comprised a significant part of the original Standards and Guidelines for NATA education programs in 1983. The competencies were based on the "performance domains" of a certified athletic trainer in the first role delineation study in 1982 (Delforge and Behnke, 1999). The 1983 Standards and Guidelines represented the NATA's first significant attempt in the development of a true competency-based athletic training education program (Weidner and Henning, 2002b).

The next phase in the transition from the 1970s to the twenty-first century was to transition from a two-route to certification, to one standard route to certification. Historically the NATA has offered two routes to certification; accreditation and internship. For students of accredited Athletic training Educational Programs (ATEPs) to become eligible to sit for the National Athletic Trainers' Association Board of Certification (NATABOC) examination, students must have demonstrated satisfactory completion of courses in the ATEP and 600 to 800 hours of clinical experience comprised mainly of contact or collision sports. In internship programs, students must have completed the minimal class set, and also have completed 1500 to 1800 hours of clinical experience also with the emphasis on contact and collision sport exposure. The significant difference in the two programs is that in the accredited programs there was 
thought to be less of a hands-on approach and more academic preparation, with the opposite holding true for internship programs. The major assumption was that the less stringent academic requirements could be compensated for by increasing the total number of hours of student exposure to the profession. Two factors that became apparent when studying this assumption was that 1) the number of clinical hours completed did not affect the outcomes on the NATABOC exam scores (Turocy, Comfort, Perrin, \& Gieck, 2000), and 2) about 60\% of the time spent in clinical experiences, the students were not appropriately engaged in learning (Miller and Berry, 2002). Regarding the first study presented above, 269 first-time candidates to sit for the 1993 NATABOC exam were included in this study. The results demonstrated that regarding the total amount of hours gained in the clinical education portion of the athletic training education, neither 1500 or 800 , predicted outcome on the exam. The same was true when high impact versus low impact hours were compared. Examples of high impact clinical education hours are those accumulated working with football, and soccer, and low impact may be sports such as baseball, or swimming. This study was very significant in that up until this point much of the focus of clinical education was based on time or on high versus low impact sports. The second study listed above reported that the majority of time that the students accrued in the clinical education setting was spent unengaged in clinical education activities related to those defined in the Competencies. In essence, there was the shift from a quantity based clinical education program to a higher focus on quality experiences. These two factors in conjunction with others promoted the NATA to move to one route to certification via accredited ATEPs. All students who planned to pursue certification via the internship route must have applied to take the certification exam before January, 2004. 


\section{Recent Trends in Allied Health and Athletic Training Clinical Education}

Overall, recent trends in allied health and athletic training clinical education include 1) progress of clinical education toward becoming more structured and organized (Jarvis, 1983; Knight, 1990), 2) expectations and responsibilities of the student, clinical instructor, and clinical education setting have become more clearly understood and delineated (Weidner \& Henning, 2002b), 3) decreases in the amount of socialization into the profession that occurs in the clinical education program (this refers to the common practice of expecting students to learn vicariously through watching professional actions of superiors) (Jarvis, 1983), 4) evaluation of the clinical education setting as a significant factor in clinical education (Weidner \& Laurent, 2001), 5) an increased attention to the student's evaluation of the clinical education setting (Weidner \& Laurent, 2001), 6) early exposure of students to the clinical setting (Irby, 1986), 7) attempts at improving public credibility, cost containment, outcome measurements, service, orientation, and cultural diversity (Bok, 1992; Seaton, 1978; Winston, 1992).

In addition to the trends that were listed above, several trends have been specific to athletic training. After athletic training became an allied health profession in 1990, a new set of Standards and Guidelines was conceived that sought not only to achieve compliance with the Commission for Accreditation of Allied Health Education Programs (CAAHEP), but also further advance the profession. These new Standards were created by the Joint Review CommitteeAthletic training (JRC-AT) and they were adopted by CAAHEP in 1991 (Weidner and Henning, 2002b). The initial Standards were approved and co-sponsored by the NATA, the American Academy of Pediatrics, the American Society of Family Physicians, and the 2001 Proficiencies, Standards, and Guidelines (to be expounded upon below) were also co-sponsored by the American Orthopedic Society for Sports Medicine. 
In 1997, the NATA Board of Directors approved 18 initiatives recommended by the Special Education Task Force established in 1994 (Weidner \& Henning, 2002b). The NATA Board of Directors established an education council. The function of this council was to enhance the credibility of the profession within the allied health fields, and to improve the education of ATSs. The most significant of the 1997 initiatives was to eliminate the internship route to certification (Weidner and Henning, 2002b).

It was from these 1997 initiatives that the approved clinical instructor (ACI) and Clinical Instructor Educator (CIE) credentials were established. These two new credentials were approved as part of the new 2001 Proficiencies, Standards, and Guidelines, which made them mandatory in accredited ATEPs. The purpose of the establishment of the CIE training was to develop a standard of training of the ACIs for the overall purpose of teaching the ACIs how to teach and evaluate the athletic training proficiencies (Accreditation Standards: Athletic Training, 2001). These courses were conceptualized because there was no longer the assumption in athletic training that all athletic trainers are inherently qualified to be clinical instructors by means of possessing an NATABOC certification.

The new athletic training competencies ( $3^{\text {rd }}$ edition) were created following the fourth role delineation study in 1992 which increased the scope of athletic training from 6 domains to 12, mainly to compensate for the ever-expanding role of the entry-level athletic trainer in the treatment of active populations. The new proficiencies synthesize similar cognitive, psychomotor, and affective teaching objectives and describe them in terms of measurable skills (Accreditation Standards: Athletic Training, 2001). The competency-based measure of a student's progress is now the standard measurement of a student's clinical preparation and 
eligibility to take the NATABOC exam, replacing the documentation of clinical hours as the standard.

\section{Recent Research Findings in Athletic Training Clinical Education}

Many students have identified the clinical education portion of the athletic training education programs as the most important part of their development of their athletic training knowledge (Laurent \& Weidner, 2002). The students studied suggested that approximately 53\% of their learning in their athletic training education programs came from the clinical education experience (Laurent \& Weidner, 2002). This finding is also significant when you recall Miller and Berry's (2002) study where the students were unengaged $59 \%$ of the time during this process. It is possible that even more learning could occur in the clinical education process with a more structured process. With the demonstrated perceived importance of the clinical education process by both certified athletic trainers (ATC)s and athletic training students (ATS)s, authors have recently attempted to verify the quality and quantity of clinical education.

Until recently the quality of the clinical education process in the athletic training and allied health professions has been determined by using qualitative analysis and describing narrowing themes and trends in the clinical education (Miller \& Berry, 2002). Miller and Berry conducted a study of ATS's use of time within the clinical education portion of the athletic training experiences quantitatively as measured by an analysis of ATSs behaviors during the clinical education portion of the curricula. Although the study had significant limitations especially regarding generalizability due to the fact that the authors used a sample of convenience at one university, and measured students at one point in time, the results were astounding. Students were unengaged $59 \%$ of the time while only $7 \%$ of their time was spent in instructional activities. To put these numbers in perspective, physical educators have consistently 
demonstrated that students spent $20 \%$ to $30 \%$ of the time waiting, and $15 \%$ to $20 \%$ of their time in management activities (Beauchamp, Darst, \& Thompson, 1990; Siedentop, 1991). Students in these studies only spent $32 \%$ to $38 \%$ of their time engaged in active learning (Beauchamp, Darst, \& Thompson, 1990; Siedentop, 1991). It is also necessary to note that these physical educators do not find these numbers acceptable. It is of great concern that the clinical education statistics in this study were far below what was deemed unacceptable in physical education. Although extreme caution should be used while applying the results to any other population, they do represent a need for further exploration.

With the demonstrated perceived importance of the knowledge gained in clinical education, in combination with the 2001 Standards that have been enacted to potentially improve the clinical education experiences, there has emerged a need to reveal an adequate picture of the current state of clinical education. Although the original 1991 Standards were revised in 2001, the clinical education proficiencies were not required to be fully implemented until 2003.

\section{The State of Athletic Training Clinical Education}

As with any implementation of new Standards, questions and concerns may arise within the first years of this implementation. One of the biggest changes with the 2001 Proficiencies, Standards, and Guidelines is the addition of the ACI, and the requirements of the 2001 Proficiencies, Standards, and Guidelines. These new requirements marked a potentially significant increase on time demands of ACIs, especially in small schools. The transition from the hourly requirement to proficiency only requirement may have produced a significant source of stress secondary to change for those institutions that were not in compliance with these Standards. The transition from the hourly requirement to the proficiency-based requirement may have also been stressful for those programs that were barely "getting by" with the old Standards. 
The transition was potentially much more feasible for the programs whose level of expected change was less significant. For example, schools that started with an hourly-based clinical education model, a school with four ACI's and no funding for additional positions may have had more difficulty with the transition than a school with $10 \mathrm{ACIs}$ and more access to funding. In the first part of the example the school was faced with two problems. The first is that four ACIs were going to have to most likely increase their workload to conform to the proficiency-based model and the potential for further assistance from the department was not possible. In the second part of the example, the school would possibly have had a less stressful time with the change, if all other variables were the same. There were more ACIs to share the increased duties, and the potential for hiring more staff was there.

To date most of the literature regarding athletic training clinical education has been professionally prescriptive in nature (Gardner and Harrleson, 2002; Harrelson \& Leaver-Dunn, 2002; Konin, Amato, \& Brader, 2002; Platt Meyer, 2002a; Platt Meyer, 2002b; Swan, 2002; Weidner, 1997; Weidner \& Henning, 2002a). By this I mean that most articles have been written about how to be a better clinical instructor (for example, Swann's (2002) article, "Communicating Effectively as a Clinical Instructor", or how to choose appropriate settings, (Laurent \& Weidner, 2002) etc. While these articles are necessary and important, they all leave out a crucial factor in the clinical education experience; the institution. If there is not institutional support, there may be many feelings of perceived helplessness. A better understanding of the current perceptions of the issues of clinical education and factors that affect the clinical education process will lead us to the determination of what the most crucial issues to address in clinical education are. There should always be continued assessment after changing or implementing any practice guideline. 
It is hypothesized that by studying these concerns within the entire affected population an accurate description of the state of clinical education process will be identified relating to: 1) the current perceptions of approved clinical instructors (ACIs) regarding the clinical education process since the implementation of the Standards and Guidelines; 2) the identification of key factors relating to the facilitation or impediment of quality clinical education; 3) the immediate needs of ACIs currently practicing in clinical education in (CAAHEP) approved programs. Factors That Affect (Facilitate or Impede) Clinical Education

In order to better understand this phenomenon, it is necessary to completely understand the issues at hand. There have been no studies published do date in peer refereed journals that have addressed perceptions of ACIs regarding the clinical education process. In fact there have been no studies published regarding this topic in any of the allied health literature. Although there have been no studies on this topic, Turocy (2002) suggested in her review of the literature in athletic training and clinical instruction in particular, that further research should include analysis of the effects of administration, personal factors, and environment on clinical instruction and student learning. The identification of factors that influences clinical education can be gleaned from the literature, and also from professional experience and intuition.

Perceived lack of time. The factor of perceived lack of time has been studied commonly as barrier to many things. Considering the variety of responsibilities for ATCs (Duncan \& Wright, 1992; Jarski, Kulig, \& Olson, 1990; Perrin, \& Lephart, 1988; Staurowsky \& Scriber, 1998), it is understandable that lack of time may be a barrier for successful implementation of clinical education. Hutchinson and Johnston (2004) studied the barrier of lack of time and its effect on the utilization of research in the nursing clinical practice setting. The results 
demonstrated that a reported lack of time is a barrier to the implementation of research in the clinical setting.

Communication skills. Communication skills have consistently been found to be an important factor being an effective clinical instructor. Research studies indicate that clinical instructors should clearly communicate their expectations to the students, as well as the objectives for the clinical experience (Dunlevy \& Wolf, 1992; Emery, 1984). Clinical instructors should also demonstrate active listening skills and ask open-ended questions that illustrate that the CI has a sincere interest in the student, which positively affects the interaction (Dunlevy \& Wolf, 1992; Emery, 1984; Laurent \& Weidner, 2001). Swan (2002) wrote a prescriptive article about how to communicate effectively as a clinical instructor. She identified communication as on of the essential components of the clinical education program. If there is not adequate communication, the clinical education process is destined for failure.

Interpersonal skills. Most of the research on interpersonal skills in clinical education has taken place in the nursing domain. For example it has been offered that an effective clinical instructor should have effective interpersonal skills (Dunlevy \& Wolf, 1992). Interpersonal skills are integral in making the student feel valued as a person (Dunlevy \& Wolf, 1992). Examples of interpersonal skills are the clinical instructor's ability to interact with students with enthusiasm, friendliness, honesty, and receptiveness (Dunlevy \& Wolf, 1992; Gjerde \& Coble, 1982; Jarski et al., 1990; Morgan \& Knox, 1987; Nehring, 1990). Modeling is another form of interpersonal skill that an effective clinical instructor should have in their professional repertoire. The clinical instructor should model professional behavior and encourage this behavior in their students at all times (Anderson, Larson, \& Luebe,1997; Dunlevy \& Wolf, 1992; Irby, Ramsey, Gillmore, \& Schaad, 1991). 
Weidner (1997) defined clinical instruction as the thoughtful proactive teaching of psychomotor skills and professional behaviors with the primary focus on the student rather than on the patient. This is one way that athletic training clinical education differs from other medical professions. In most of the reimbursement oriented medical professions (i.e. medicine, nursing, physical therapy, and occupational therapy) the focus of the clinical education process is always the patient first. Swann (2002) identified the "communication pathway" as a communication process that starts with the clinical instructor and then proceeds directly to the patient, or the student. If the communication goes the route of the student, the next step in this process is either back to the clinical instructor or the patient. The key concept here is that the clinical instructor in the clinical education setting has one responsibility. This responsibility is to guide the student in becoming a competent clinician while providing a safe environment for both the student and the patient.

Leadership skills. Platt-Meyer (2002a) reported that leadership skills and abilities have a direct influence on whether a clinical instructor is considered effective or not. Clinical education is similar to other professions in that characteristics that are found in effective clinical instructors are also found in effective leaders (Brown, 1981; Fong, \& McCauley, 1993). Leadership skills are also important in clinical education because effective leaders know the educational and skill level of their students or employees, and therefore make appropriate recommendations that are meaningful and constructive. Platt-Meyer advocated using the student's developmental level to determine the type of leadership skills that the clinical instructor chooses.

Platt-Meyer (2002a) also developed an original tool to assess clinical instructor effectiveness using five constructs of leadership behaviors: 1) professional attitudes, 2) professional actions, 3) communication skills, 4) teaching abilities, and 5) personal attributes. 
Forty-three students completed questionnaire to evaluate clinical teacher effectiveness. When the five categories of teaching behaviors were assessed together, they suggested clinical instructor effectiveness. When examined separately, professional attitudes, professional actions, and communications skills were statistically significant. This indicated that professional attitudes, professional actions, and communication skills could be evaluated to determine clinical teaching effectiveness.

Supervisory skills. Effective clinical instructors demonstrate high quality supervisory skills. This includes the ability of the clinical instructor to relate to each student at the student's current educational level. The clinical instructor must be able to deliver quality direct supervision. Quality direct supervision can be defined as clear appropriate expectations, direct observation within eyesight and earshot, and feedback directly related to performance that takes into consideration the student's educational level and affective well being (Laurent \& Weidner, 2002). Clinical instructors (Cls) should maintain a balance between providing feedback and fostering student autonomy (Anderson et al., 1997; Irby et al, 1991).

Ability to change practice. Hutchinson \& Johnston (2004) identified in a study a barrier of a perceived inability to change their practice. The nurses that responded to the questionnaire felt that change was out of their hands. This expression of perceived helplessness is common and is most related to relationship with administration and or peers.

Administrative support. Laurent and Weidner (2002) identified administrative support as a factor that is necessary for athletic trainers to effectively contribute to the clinical education process although they offered no research evidence to bolster their claim. Administrative support can take the form of a reduced workload for clinical instructors (Laurent, \& Weidner, 2002). Accreditation Standards and Guidelines require that appropriate resources be available to operate 
the educational program (Accreditation Standards: Athletic Training, 2001). Laurent and Weidner (2002) suggest that these same requirements should exist for the clinical education part of the program.

Motivation. Motivation of the ACI as a factor affecting the clinical education process has been reported in the literature. Foster and Leslie (1992) reported that the clinical instructors solicited for the study reported that they enjoyed the clinical education process, and cited a sense of responsibility as a motivating factor. At the time of this study athletic training clinical instructors spent approximately 21 hours per week engaged in clinical instruction related activities, and this hour number is expected to have increased with the required implementation of the 2001 Proficiencies, Standards, and Guidelines in 2003. The overall effect on an ACI's motivation may prove to be significant.

Formal teacher preparation and clinical teaching experience. The effects of teacher preparation have been discussed in the literature as a factor that influences clinical education (Foster \& Leslie, 1992; Weidner \& Laurent, 2001). Clinical instructors with more than six years of training found more time for clinical teaching, and also the teachers with teacher certification felt more confident with academic preparation than did non-teachers (Foster \& Leslie, 1992). It was also found in this study that clinical instructors with academic training in teaching used more of a variety of instructional methods than did non-teachers. It was also found that teacher centered styles of teaching were used more regularly than student-centered styles of teaching. With these findings, one may speculate that if student centered instruction potentially fosters more of a tendency toward lifelong learning, and clinical instructors with academic training as teachers used more of the student centered models, teacher training may be indicated. It is necessary to note that this source, although frequently cited in the literature, was published in 
1992 and the information contained in it may no longer be accurate. Weidner and Laurent (2001) suggested that clinical instructors should have some knowledge of teacher pedagogical principles, and therefore, be able to implement objectives and evaluate student performance.

Clinical instructors should demonstrate effective instructional skills during the clinical education process (Weidner and Henning, 2002a). The CI should teach to encourage problemsolving and critical thinking, not just factual recall (Jarksi et al., 1990). CIs should provide well organized instruction while using clear educational objectives (Dunlevy \& Wolf, 1992; Emery, 1984) while creating a positive learning environment (Curtis, Helion, \& Domsohn, 1998).

Student supervision experience. Clinical instructors with more experience have reported having more time for teaching in the clinical setting (Massie, 2000). Along with this perception of more available time, Stemmans and Gangstead (2000) concluded in their research study that athletic training students initiate behaviors less frequently when supervised by novice clinical instructors. Novice clinical instructors in this case were clinical instructors with less than one year of clinical instructor experience. In this study, student "behaviors" were behaviors that have intuitively been associated with a high potential for student growth. This study used a sample of convenience and it is should be noted that the years of experience that was used to determine experience level, were years of experience as a clinical instructor, not just years of experience as an ATC.

Evaluation and assessment skills. Assessment of student performance is critical component of clinical education. Ende (1983) identified that feedback is necessary during the clinical education process to teach students appropriate patient care. Without good feedback good performance goes unrewarded, and bad performance goes uncorrected (Weidner and Henning, 2002a). Effective clinical instructors often engage in formative and summative 
evaluations (Weidner and Henning, 2002a). Formative evaluations are usually provided during the clinical education process and summative evaluations assess the student's overall progress and are typically performed at the middle and the end of the process. Knowledge of evaluation instruments is vital to the clinical education process. These instruments allow the clinical instructor to provide direct feedback based on objective measures.

ACI to student ratio. Laurent and Weidner (2002) indicated that respondents to their survey suggested that a low student-to-clinical instructor ratio would be very helpful in clinical education. CAAHEP Standards and Guidelines recommends no more than an 8:1 student to ACI ratio for most situations, but a 1:1 ratio is mandatory for any documentation of clinical proficiencies to occur (Accreditation Standards: Athletic Training, 2001). A higher student to ACI ratio may make it more difficult for the ACI to find adequate time to evaluate clinical proficiencies while they are, at the same time, responsible for the other ATSs, and athletic training coverage.

Clinical competence. Although the NATABOC examination is the standard process for ensuring entry-level competence in athletic training, not all clinicians are equally competent and confident. Students have identified clinical competence as a factor that is commonly found in their perceptions of effective clinical instructors (Curtis et al, 1998; Morgan \& Knox, 1987; and Nehring, 1990). Clinical instructors who demonstrate high levels of clinical competence often have more systematic approaches, and therefore may be able to pass the information on in an organized manner (Emery, 1984). It is necessary to note that these studies used student's perceptions of their clinical instructor's competence and confidence.

Relationship with students. It has been documented in the physical therapy and athletic training literature, that students perceive good communication skills on the part of the clinical 
instructor as a very important indicator of clinical instructor effectiveness (Emery, 1984; Swan \& Walker, 2001). Good communication skills are also essential in fostering good relationships between the ACI and the students. The way that an ACI interacts with the students can impede or facilitate student learning in the clinical setting (Jarski et al., 1990; \& Curtis et al., 1998).

Facilities and adequate space. The CAAHEP Standards and Guidelines stated that there needs to be adequate space for performing clinical education (Accreditation Standards: Athletic Training, 2001). Although space is not the only determinant of the quality of a facility, it has been described as one of the most important features of the facility (Kennedy 1999, 2002; \& Tinto, 1997). The physical environment can facilitate or impede collaborative learning (Metcalf, 2000; Tinto, 1997), as well as student supervision (Laurent \& Weidner, 2002).

Administrative skills. Effective clinical instructors often have very advanced administrative skills (Emery, 1984). Critical components of effective administrative skills are the ability to manage time and appropriately delegate responsibilities (Emery, 1984). Morgan and Knox (1987) also reported that the majority of students felt that organization and administration are important skills in clinical instructors. It is necessary to note that these findings were also based on student perceptions of their clinical instructors.

Job satisfaction. Although the study of job satisfaction can be very difficult to research because of the multitude of factors that contribute to the phenomenon, it should be considered when identifying factors that may impede or facilitate clinical education. Staurowsky and Scriber (1998) noted that athletic trainers are set apart from other faculty at their institution because of the diverse nature of their employment. Factors that have been linked to job satisfaction are compensation, enjoyment, and recognition. If any of these factors are low, there is an increase potential for decreased job satisfaction. In the case of this study, it may affect clinical education. 
Department support. Perceived support from their department may be an important factor that contributes to the delivery of clinical education. Although one study (Staurowsky \& Scriber, 1998), found that ATEP programs surveyed had at least three ATCs employed, they commonly averaged 51-55 hours of work per week. They recommended that institutional decision makers (provosts, deans, department chairs, and athletic directors) and athletic trainers may wish to evaluate strategies to reduce these workloads to possibly decrease the amount of perceived physical and emotional stress related to employment. Other related professions such as physical therapy have also examined the role of departmental support in clinical education.

Communication with other faculty and staff within the athletic training curricula. Starkey (2002) in a commentary on curriculum development cited the need for athletic training clinical staff and faculty to communicate with the classroom faculty and staff. Starkey discussed the idea that a lack of communication between classroom and clinical instructors stands to create an "us versus them" mentality that is unhealthy for the profession and department. Authors have discussed potential reasons for the "us versus them" mentality (Carr \& Drummond, 2002). Clinical tend to be younger, paid less, and not trained in education practices. To add to these potential factors there has been an unnatural separation between classroom and clinical instructors. In the recent past, classroom instructors and clinical instructors were one in the same. Now there is a separation of these two groups of instructors based primarily upon job descriptions. Starkey stated that the tendencies are now for the classroom instructors and clinical instructors to be hired through different departments. For example, many classroom instructors are hired through academic departments and many clinical instructors are hired through the department of athletics. This creates two main problems. The first problem is that the natural separation encourages a lack of communication between the two groups. The second problem is 
that the two departments have distinctly different missions. The mission of the academic departments will be more in line with the mission of ATEPs. The primary purpose for the ATCs in the athletic department, of course will be to provide athletic training services to athletic teams. In this setting clinical education may be seen as part of the job description as long as it does not interfere with their primary (coverage) responsibilities. In each setting, the university employed athletic trainer, will answer to a different administrator, with different criteria for promotion and continued employment (Starkey, 2002).

As stated in Chapter One, clinical education is the portion of the program where theory meets practice. The athletic training curriculum is very complicated in that the classroom teachers are responsible for the initial knowledge and skills and the clinical education staff are responsible for the integration of the knowledge and skills into the practical setting. The "us versus them" philosophy is sometimes exacerbated through the relationship between the classroom teachers and clinical instructors in this setting if adequate communication does not take place. If there is not agreement between the classroom and clinical instructors the students may sense this, and in turn this may cause a potential for problems (Starkey, 2002). Starkey also stated that the responsibility for bridging any gaps in communication rests with the academic staff, especially the program director.

\section{Demographic Characteristics of ACIs}

There has been no demographic information collected specifically on ACIs and little on the demographic characteristics of athletic trainers at ATEPs. Part of the reason for this is because many times ATCs job responsibilities entail more that only clinical instruction. Another reason is that there is a dearth of information on ACIs is because the term is new ACI and was created in 2001. Yet another possible explanation of why there is little demographic information 
available about athletic trainers in the educational setting is that so many of the athletic training related studies use a sample of convenience or are in some other way methodologically weak such as a small sample from a particular geographic area, or a sample delimited by other factors such as institutional size, division (I, II, III) etc. Below is most of what is currently known about the demographic characteristics of ATCs, and in many instances clinical instructors. I will try to specify the purposes and the contexts under which the information was gleaned.

Staurowsky and Scriber (1998) developed a survey to analyze the work lives of athletic trainers employed in accredited ATEPs. Based on the data, the ATCs surveyed described that about $40 \%$ of their workload consists of teaching responsibilities, $30 \%$ dedicated to service to the athletic department, and 30\% to student supervision. Among program directors $50 \%$ did have clinical education responsibilities, and 50\% did not. Ninety-three percent of ATCs surveyed in this study reported working more than 40 hours per week, and the "average" ATC worked 51-55 hours per week. Sixteen percent reported that they worked 60 or more hours per week.

Foster and Leslie (1992) reported, using a sample of 197 Midwestern athletic trainers employed in the university setting with a cross-section of experience levels that: 1) Sixty-three supervised students as part of their job description, 2) athletic training services and student supervision accounted for more than 20 hours per week, 3) of the 80 ATCs who taught clinically, 70 taught ATSs for less than 50\% of their work week, 4) ATCs used mainly a combination of lecture, telling, and presenting. ATCs surveyed also reported that they felt a sense of responsibility to teach students how to practice in the athletic training setting. They cited that in general, they enjoy teaching clinically, and held it of equal importance as the rest of their responsibilities. The respondents felt somewhat academically prepared to teach clinically, they believed that they had time to do so, and they also felt that clinical teaching was not difficult. 
Respondents were not certain of the similarity of teaching in the classroom to the clinical teaching setting.

The following results should be viewed with caution, as sample sizes for ANOVAs used sometimes were too small. Other results indicated that ATCs with at least a master's degree, felt more comfortable with teaching responsibilities (Foster \& Leslie, 1992). ATCs with more than 6 years of experience felt that they had more time for clinical teaching, and respondents with teaching degrees placed higher importance on clinical teaching than did non-teachers. Teachers with academic training felt more comfortable in their clinical teaching role and generally disagreed with the statement that clinical teaching is difficult. ATCs with teaching degrees also were more likely to agree with the statement that the clinical teaching setting is similar to the classroom teaching setting. (Foster \& Leslie, 1992).

Although some of the information presented above is not truly demographic information, it is necessary to report the results of that study to demonstrate how some of the demographic information collected has been used to contribute to the general knowledge of the state of clinical education. As stated above the knowledge of demographic characteristics has been limited by the methods employed in these studies. It is also necessary to note that the information collected in Foster and Leslie's (1992) study probably no longer represent the clinical teaching roles of athletic trainers.

There has been much change in the 12 years from when the study was published until now. There have been many changes to the existing structure of the athletic training program since then, including the elimination of the internship route, a decrease in the percentage of athletic trainers graduating with a teaching degree, a separation of the academic and clinical settings by nature of the department through which the ATCs are housed, and lastly the changes 
that have occurred as a result of the implementation of the revised 2001 Proficiencies, Standards, and Guidelines.

Steps for Improvement of Clinical Education

Improvement of student supervision. In Toburen's commentary in the 2002 Educational Supplement of the Journal of Athletic Training, the author gave her opinions of the state of the process and steps that can be taken to improve clinical education. She noted that more ACIs are graduating from undergraduate experiences without teaching degrees or experiences. She also underlined the fact that not all athletic trainers at potential clinical education sites want to be ACIs. Toburen suggested that 1) students should be assigned to clinical supervisors and not sites, (this is also stated in the revised 2001 guidelines) 2) less students should be assigned to ACIs, and 3 ) these students should only be assigned to ACIs who are competent and educationally committed. This seems to be a good idea, but ATEPs that existed before the implementation of the 2001 Proficiencies, Standards, and Guidlelines may have many ACIs that are not necessarily educationally committed. How do these programs deal with this issue? It may be a long process to get only competent, educationally committed ACIs involved with the clinical education process.

Weidner and Pipkin (2002) reported a need for improvement of athletic training student supervision at colleges and universities. Weidner and Pipkin reported that $55 \%$ of head athletic trainers surveyed, reported that ATS were permitted to provide medical care and athletic training duties without direct ATC supervision. Under the revised 2001 Proficiencies, Standards, and Guidlelines (which were not fully in place at the time of this survey) this is not permitted. ATSs now can only provide the emergency care consistent with the professional credential that they currently hold, which in most cases is that of a first responder. A first responder can initiate an 
emergency action plan and provide necessary first aid and cardiopulmonary resuscitation (CPR) until the arrival of more qualified medical personnel. At no time are students permitted to perform duties of a credentialed ATC without direct supervision of an ATC. An ATS is considered unsupervised if a CI cannot arrive to the scene within four minutes of an incident. Unfortunately this phenomenon is not uncommon in other allied health literature. Polifroni, Packard, Shah, and Macavoy (1995) reported in a study that utilized non-participant observations, that approximately $75 \%$ of the time in clinical practicum setting is spent practicing unsupervised. The clarification of the 2001 Proficiencies, Standards, and Guidelines represents the potential to greatly improve the quality of ATS supervision. Davis and Misasi (2001) reported that athletic training students are frequently regarded as part of the athletic training staff, because they are often a more familiar face than the supervising ATC due to an overload of the responsibilities of the CIs. With the implementation of the revised 2001 Proficiencies, Standards, and Guidelines ATEPs that are in compliance with the Standards will no longer have students who are looked upon as a member of the athletic training staff.

Organizational improvements. Toburen (2002) noted that over-assigning students to overworked ACIs does not decrease the workload of the ACIs clinical responsibilities but if the clinical education process is done properly it increases the workload. Toburen also suggested that graduate students (GAs) serving as ACIs should be carefully selected and monitored based on their maturity and commitment to education. This comment was research defended in athletic training studies involving clinical instructor experience (Massie, 2000; Stemmans \& Gangstead, 2000). Toburen noted that stability in the clinical education setting is necessary and this is impossible to achieve with the high turnover rate of graduate assistants. Toburen also discussed the need to make administrators aware of the uneven consequence and reward balance of hiring 
graduate assistants (GAs) to increase the amount of ACIs and decrease the amount of money needed to fund these positions. The reward of decreased cost for the institution is not nearly as much as the consequence of hiring GAs in the place of experienced and proven clinical education faculty members. Toburen also suggested that the didactic and clinical education coordination needs much improvement.

Toburen stated that clinical education might be improved if the ATEP programs are housed in the same college with the other allied health professions that share a similar clinical education process. In this case the college will already be aware of difficulties that the clinical education programs face such as clinical education release time and compensation. She stated that although organizational factors at first may only seem peripherally related to the topic of clinical education, administrators who are aware of the many factors that separate programs with clinical education components to those without those components may be better. She stated that education of administrators is necessary to obtain the appropriate funding for the hiring of appropriately qualified clinical education faculty.

Establishment of clinical education faculty. Toburen (2002) stated that clinical education faculty positions should be developed to improve the quality of educators attracted to this portion of the educational program. These positions would enable the clinical educators to spend more time in clinical education only duties. These positions would be similar to the athletic training faculty who has limited other responsibilities other than teaching.

Focus on student learning. Toburen (2002) stated that the primary concern for clinical education is the professional development of ATSs, and if the institutions are going to meet the challenge of understanding and implementing the competency and proficiency based education, 
the emphasis must be made on the quality of the learning experience and individual instruction. She has also noted that student learning is of primary concern even for higher-level students. One study (Stemmans \& Gangstead, 2000) demonstrated that the amount of direct supervision decreases as the student progresses through the athletic training curriculum. As the student progresses through the curriculum they gain a better, more complete understand of athletic training, blending theory and practice. To relegate the advanced students to the role of first responder because the university does not have enough money to fund proper supervision is not acceptable.

\section{Collaboration between classroom and clinical instructors. Collaboration between} classroom and clinical instructs is paramount to the education of ATS. Carr and Drummond (2002) examined the amount of collaboration that took place between classroom and clinical instructors. For this study collaboration was measured by three components: 1) physical presence, 2) communication, and 3) cooperation. Classroom instructors perceived (perceived since the construct required an estimate of past activity) a higher amount of observed cooperation between classroom and clinical instructors. This is important because it may signify a perceived inequality between classroom and clinical instructors. Carr and Drummond recommended further research on collaboration at the institutional level. Improving the collaboration between the classroom and clinical instructors may improve the clinical education process.

Improvement of Pedagogical Strategies. There has been a decreasing trend of athletic trainers graduating from ATEPs with a teaching certificate, or even with knowledge on basic pedagogical principles (Toburen, 2002; and Foster and Leslie, 1992). Athletic training educators and researchers have made an effort to improve clinical education practices by using prescriptive articles (Gardner and Harrleson, 2002; Harrelson \& Leaver-Dunn, 2002; Konin et al., 2002; 
Platt-Meyer, 2002a; Platt-Meyer, 2002b; Swan, 2002; Weidner, 1997; Weidner \& Henning, 2002b). Such articles choose a pertinent topic, describe that topic, and follow that with examples of how to implement the strategies that were described. For example, Weidner and Henning (2002a) described in their article how to be an effective clinical instructor. The introduction of the article established the need for such an article. The body of the article identified nine common qualities, characteristics, and skills for effective clinical instructors. The summary described how practicing ACIs could incorporate these concepts into their own clinical education teaching practices.

In summary, there has been a fair amount of literature published in clinical education and more specifically in athletic training clinical education, but there continues to be a quantity of unknowns. There has been no research on the state of clinical education from the perceptions of the ACIs. More importantly there has been no formal analysis of the impact of the revised 2001 Proficiencies, Standards, and Guidelines. Although many factors that affect clinical education have been mentioned in the literature, there have been no studies that have examined the factors that facilitate or impede the clinical education process from an individual professional view. There has never been a published needs assessment for athletic training clinical instructors. ACIs may have different needs than ATCs in the didactic setting. There is also a lack of recent literature regarding demographic characteristics of ACIs. 


\section{CHAPTER 3}

Methods

\section{Introduction}

One purpose of this study was to identify the demographic characteristics of ACIs in currently Commission on Accreditation of Allied Health Educational Programs (CAAHEP) approved accredited athletic training programs (ATEPs). A second purpose of this study was to assess perceptions of the clinical education process since the implementation of the 2001 Proficiencies, Standards, and Guidelines. A third purpose of this study was to determine the critical factors that facilitate or impede the quality implementation of the clinical education process. A fourth purpose of the study was to identify key factors or steps for improving the quality of the clinical education process. The methods that will be described in this chapter will include the following sections: 1) participants; 2) pilot research; 3) survey development; 4) procedures; 5) hypotheses; and 6) data analysis.

\section{Participants}

There were 212 participants in this study. The entire population of full-time faculty and staff approved clinical instructors (ACIs) serving as ACIs in CAHEEP accredited athletic training programs were invited to participate in this study. The complete listing of the 298 CAAHEP approved accredited athletic training programs can be found at www.caahep.org. In an attempt to survey those ACIs who are the major stakeholders and those who have the most experience in athletic training and clinical education, the researcher intended to exclude parttime employees, graduate students, and off-site ACIs (Lauber et al, 2003); although a few ACIs that did not meet this criterion did respond. 
Institutional Review Board for the Protection of Human Subjects (IRB) approval was attained for pilot studies one and two, and was also obtained prior to collecting data on participants in the final survey. The participants were not required to submit their name or any other identifying characteristic in an effort to maintain anonymity. Each school's identity remained anonymous. The researcher asked program directors to explain to the other participants that they were to fill out the online questionnaire via the web link. A cover letter was provided on the webpage that explained the individual's rights as research participants and also contained the survey link on the bottom of the webpage.

\section{Pilot Research}

There were two pilot studies that were performed with the intention of making the survey more functional and user friendly. The first pilot study consisted of the "factors" (Appendix E) in Part Two, which were sent to nine experts in the field. The experts that were chosen for this study have been key researchers in the area of athletic training clinical education in the past decade. The nine experts were sent Part Two of the survey. They were asked to comment on the factors that were already present, add to the list, or eliminate any items that might not be necessary. They were informed of the purpose of the factors in the final survey. Five out of nine experts returned the study to an unbiased third party in order to not identify them to the researcher. The pilot study was very useful as the experts made many suggestions. The suggestions ranged from minor grammatical and semantic changes to additional factors that should be added to the list. All comments were positive and they were all reviewed for their potential utility. Changes were then made to the survey that was given as Pilot Two.

The second pilot study aimed at improving the validity of the questionnaire. This was done by issuing the questionnaire to ACIs within the CAAHEP accredited athletic training 
education program at West Virginia University during the end of semester retreat. Since these ACIs contributed to the final version of the questionnaire, this institution was left out of the final population do to the possible effects of multiple testing and familiarity. The second pilot study had three main purposes. The first purpose was to have the group complete the questionnaire and report the time it took to complete. Brief analyses were performed on the data after the pilot survey. The second purpose was to identify any unclear or confusing questions. The third purpose of the second pilot study was to familiarize the researcher with the potential responses to the survey. This enabled the researcher to decipher whether all needed information was obtained, and also whether or not it was functional, meaningful data.

Nine ACI's completed the survey (Appendix F) at an end of semester athletic training retreat. Seven out of nine ACI's reported that it took between six and ten minutes to complete the survey. Since it was such a small sample, it was unclear whether the pilot would produce results that would be similar to the results that used the full population, therefore a brief report of the second pilot will be addressed. Also included was any feedback that was issued at the time of this pilot. Part One of the survey asked questions regarding ACIs perceptions of the clinical education process since the implementation of the 2001 Proficiencies, Standards, and Guidelines. Mean scores on the Part One questions ranged from 3.29 to 5.33 on a scale that ranged from 1 strongly disagree to 6 strongly agree. All questions in Part One were developed to read in a positive manner to improve the readability of the study. Only two questions leaned toward disagree on the scale. It was unclear at the time of the pilot study whether or not these results would be true for the larger sample obtained in the final study.

The literature suggested that the implementation of the 2001 Proficiencies, Standards, and Guidelines represented a significant change to the ACI's practice. Question number two, in 
Part One examined this thought. The mean of the sample confirmed this by reporting an average of 5.33 out of a possible six. Questions number six and eight received the lowest scores. Question six addressed the participants' having enough time to properly implement Learning Over Time. Therefore it is no surprise that this received the lowest agreement score, as time has been consistently shown to be a significant barrier. It is interesting to note that question number eight, "The important factors in clinical education are within my control" was the second lowest scoring response in Part One. This is interesting because the general trends of this small group were positive, yet the ACI's in this sample perceived a lack of control of the factors that affect the clinical education process. The next logical step from this point was to identify those factors, which naturally lead to Part Two.

Part Two was designed to evaluate the factors that impede or facilitate the clinical education process. Thirty-one such factors were listed and the participants were asked to rate the scores on a continuum from -3 (impedes) to 3 (facilitates). The mean scores for the thirty factors ranged from -.25 to 2.25 . Over half of the factors received at least one negative (impedes) score. This represents variability between ACI's, which was expected, but the cause could not be determined at the time of this pilot study. Once again, Learning Over Time received a negative score at -.25 (impedes). This may relate to the significant amount of time that this process takes. The ease of documentation of the proficiencies received a negative score-.11 (impedes). The implementation of 2001 Proficiencies, Standards, and Guidelines definitely increased the amount of documentation of the proficiencies required as a part of the clinical education process. Interestingly the two factors receiving the highest score related to the relationships with the program director and the clinical education coordinator. These indicated personal factors related 
to the clinical education process, rather than the lower institutional or policy factors such as documentation of the proficiencies and Learning Over Time.

Part Three of the survey related to the factors that would be most beneficial to address, in order to improve the clinical education process. Eighteen different factors were selected with the one factor receiving three votes, six factors receiving two votes, and eleven factors receiving one vote. It was not surprising that the factor that received the most votes was related to time allotted for clinical education administration. In fact, in this small sample, many of the factors that related to time were most constraints were most likely to be selected $(12,20,32,33)$.

Since this study involved such a small relatively homogenous sample the results of the demographics questions were most likely insignificant, therefore reporting these would most likely not have lead to a better understanding of the clinical education process. However, the researcher did determine that certain questions might provide more useful data if mean scores were used rather than range frequencies. This proved to be especially useful when describing the population. It is always possible to apply the ranges after collecting those data. These data were initially collected as frequencies of ranges to improve the user friendliness of the instrument, although this effect was believed to be minimal and the overall value of true numbers may be more useful than the potential benefits from the improved user-friendliness of the survey.

\section{Survey Development}

This study employed one information-gathering survey. The survey (See Appendix J) contained four main parts $(1,2,3$, and 4$)$. The survey was developed to gain insight into ACIs' perceptions of the clinical education process. Part One was designed to identify the ACIs' perceptions of the clinical education process since the implementation of the 2001 Proficiencies, Standards, and Guidelines. These questions were evaluated on a six-point Likert scale from 
"strongly disagree" to "strongly agree". The six-point Likert scale was chosen because all of the statements are worded in a fashion that promotes an agree or disagree response. There was no need for a neutral response with these types of questions because all ACIs should have an opinion regarding these questions. Since Part One of the survey contained statements that are applicable to all ACIs secondary to the requirements of the 2001 Proficiencies, Standards, and Guidelines there was not need for a not applicable (N/A) response choice.

The questions were developed through exploring the literature, consulting with experts, and evaluating the changes that may have resulted from the implementation of the 2001 Proficiencies, Standards, and Guidelines. All items in Part One were created by evaluating the potential changes that may have resulted secondary to the implementation of the 2001 Proficiencies, Standards, and Guidelines and as a result of speaking with ACIs about how they were most effected by the implementation of the mandates. Since this topic has never been researched there was not solid literature base from which to develop these questions.

Five out of the nine questions (questions 1, 2, 5, 7,8) in Part One of the survey were designed as general global indicators of ACIs' perceptions of the clinical education process since the implementation of the 2001 Proficiencies, Standards, and Guidelines. The remaining four questions $(3,4,6,9)$ were designed to identify more specific portions of the clinical education process since the mandates. It was unclear whether or not there would be a difference between the responses to these statements.

Part Two contained factors that were identified from the literature and also factors added from the pilot study results; including expert opinions. The participants were asked to evaluate the factors on a seven-point Likert scale from "impede" to "facilitate". This scale contained a neutral response choice since it was possible for the participant to feel that there is enough 
variation of the factor that it was impossible to choose either the impede or facilitate choices. The participants also were able to check N/A to questions that are not applicable to their situation. For example, a Program Director's relationship to themselves (item 29) was not of interest to the researchers.

The factors listed in Part Two can be divided into two main categories; personal and institutional/policy related. Personal factors (items 10, 11, 13-18, 23, 26-31, 34, 36, 37, 39) related to factors of which the ACIs may be in direct control. The institutional factors $(12,19-22$, $24,25,32,33,35,38,40)$ represent factors related to the clinical education process over which ACIs may be able to exhibit indirect control.

Since this was an exploratory study and no studies have been conducted to determine the factors for Part Two, liberties have been taken and research was scoured for potentially related themes. For example none of the factors listed in Part Two were explored in one study extensively. In exploratory studies, such as this, it is more important to include factors which may not be as important to the process, than to leave out factors because they have not yet been reported in the literature. Hopefully, because of these liberties, new factors will emerge as being important to the clinical education process. Follow-up research will be able to study these factors and have empirical evidence of their relationship to the clinical education process.

Chapter Two identified themes, which have been studied in related literature, and in most instances in athletic training. Time has been studied in many domains, and has been a component of several studies in athletic training (refer to page 26). Several of the factors listed in Part Two $(12,19-21,23,32,33,38)$ of the survey were designed to address this construct. The construct of personal and professional relationships has been addressed both directly and indirectly in the 
athletic training literature (refer to pages 27, 28, 32). This construct was addressed in several Part Two questions $(26-31,39)$.

The construct of communication has been addressed in the athletic training literature (refer to pages 26-28, 33, 34) and was assessed in this survey in factors 31, 36, and 37. Leadership and supervision were very visible constructs that have been reported in the literature (refer to pages $26,28,30,31$ ). These related constructs were assessed in this study in factors 21 24 , and 36.

As reported in Chapter Two (refer to pages 29-31) teaching confidence and formal teaching preparation have been reported to be factors pertinent to the clinical education process. This construct was addressed in factors 14-16, and 37.

Job satisfaction has not been studied in the literature as an entity unto itself, but it can be argued that many of the constructs that have been addressed in preceding and future paragraphs are directly related to this construct. The next factors to be addressed may be grouped as institutional or as dictated by policy.

Another important factor in the clinical education process is administrative support. This construct has been reported in various forms (refer to pages 29, 32, 33) and was addressed in factors 10, 11, 19, 20, 32, 33, 38. Facilities, adequate space, and type of sport have been studied in the literature (see page 32) and were assessed in factors 22-25.

Other factors, although not yet studied in previous literature, were added to Part Two of this survey, after communication with experts, and evaluation of the 2001 Proficiencies, Standards, and the Guidelines to the implementation of these Standards.

Part Three asked the participant to recall the five factors from Part Two that they consider the most important to first address for improvement of quality clinical education. The results of 
Part Three were used to identify important factors to address in future athletic training clinical education research.

Part Four identified the demographic characteristics of the respondents and contained information pertinent to research question number four: "What are the demographic characteristics of ACIs currently participating in clinical education at CAAHEP accredited approved athletic training education programs?" The lists of demographic characteristics that are germane to this study were identified in the review of literature. Since this topic has never been studied in this context, there may be instances where demographic characteristics were added from the professional guidance of my committee members. Additionally, demographic characteristics of the sample were added to assist in explaining the results of Parts One through Three. For example time spent in clinical education related responsibilities or percentage of contractual agreement allotted to these activities may help to explain why ACIs rated factors related to time as lowest facilitators.

Demographic characteristics were also used to help determine whether or not the sample was representative of the population, therefore the more pertinent demographic information collected, the stronger the evidence. All parts of the survey were developed based directly from the research questions and the review of literature. The questionnaire included only those items that were considered germane to the research questions. Efforts were made to improve the validity of the survey, from the literature, through suggestions from committee members, and the pilot studies.

Survey Methodology Factors

Coverage and sampling error. Design principles for Internet surveys were followed to ensure greatest participant response rates and therefore reduce coverage error. For example, 
participants were invited to complete the survey from, an email contact directly from the researcher, an email from the Athletic Training Education Listserve, or from directly reading the listing on the Listserve. All participants were encouraged to forward the contact email to other ACIs. The multiple methods of contact that were discussed above were used, following Dillman's suggestions in, Mail and Internet Surveys (Dillman, 2000). Although all cover letters were generic in nature and were not individually addressed, participants were not able to see the list of other participants that received the contact emails. Dillman (2000) suggested that it is best to personalize the contact emails, or at least not display other addresses of potential participants. This was accomplished in this study be sending the initial contact email directly to the researcher and the participants were listed as blind carbon copies (Dillman, 2000). There is currently no evidence that sending a general letter is less effective than sending a personalized letter therefore this suggestion was not followed. Sampling was far less of a concern in this study than coverage error, because the entire population was the recruitment goal of this survey, thus making sampling error a moot point.

Measurement error. Measurement error was controlled for by: 1) constant review of fellow ATCs and committee members during the design phase of the final survey; 2) after survey completion, the factors were mailed to the list of experts (Pilot Study One); 3) sampling one entire ATEP regarding readability, flow, content, and individual constructs (Pilot Study Two; and 4) obtaining input from committee members.

\section{Cover Letters}

The cover letters (See Appendix A-D) were made as brief as possible in effort not to lose participants before they made it to the survey. The cover letters explained about the researcher and research, notified the participants of their right as research participants, and gave them 
directions and instructions to follow. The web survey also contained a very brief cover letter for those who had not seen the emailed cover letter. The web Survey cover letter contained similar information to the emailed cover letter.

Web Survey Design

Special considerations were made when the paper survey was converted into a Web Survey. Most of these adjustments involved the final display properties of the web survey and overall user friendliness and did not include changes to the content of the survey. As noted above the Web Survey contained a cover letter/ consent form with a direct link to proceed to the survey. The original Paper and Pencil Survey was white paper with black type-face (See Appendix G), while the Web Survey (Seen Appendix H) used white and blue coloring to differentiate question numbers and improve the ease of completion (Dillman, Tortora, \& Bowker, 1999). Light blue was selected in order to not distract the participant. The initial Paper Survey contained directions at the beginning of each section or at the beginning of each page as necessary. The Web Survey contained the directions prior to each section, and also repeated the scale every few questions to facilitate survey completion. Also following Dillman's suggestions, answers to each question were not required to move on to the next question. This was done to prevent attrition. Instead, a blank response was added to the end of each question, and was automatically filled in. When the participant chose another response for that question, that response changed from the blank response to the entered choice. The blank response choice was invisible to the participants. All survey questions were contained on the same page and participants were able to scroll anywhere on the page. This gave the participants a chance to skip and return to questions, and it also eliminated possible glitches that may have arisen from switching screens and constant refreshing of Browser windows (Dillman, Tortora, \& Bowker, 1999). Finally, the Web Survey was tested in 
a variety of Internet Browsers to determine appropriate length of question lines. This was done to decrease the likelihood of Browser difficulties leading to non-completion of the survey (Dillman, Tortora, \& Bowker, 1999).

\section{Procedures}

All program directors were emailed with a brief description of the study and a web link that they were asked to forward to all ACI's in their program (Appendix G). The participants were not required to submit their name or any other identifying characteristic in order to maintain anonymity. Participants were informed that their institution's responses would remain anonymous and they were asked to not discuss the survey with colleagues before completing it (Appendix F). The questionnaire had all of the appropriate directions before each section as necessary. After the questionnaires were completed the data were entered into a database, and Statistical Packages for the Social Sciences (SPSS) was used to analyze the data.

One week from the initial emailing, a reminder email was sent to all participating programs. This email served to: 1) remind program directors of the study; 2) reinforce the importance of the study; 3 ) thank all who have already completed the necessary information; and 4) ask the program directors to remind all participants who have not completed the study to please do so (Turocy, 2002). A second reminder was sent two weeks after the initial email. During this second week, a link with directions for completion was placed on the AT Education Listserve. Participants were asked to forward this link to colleagues and to try and encourage responses. Participants were asked not to complete this survey if they have already completed it previously. One week following the link placement on the Listserve a reminder was also added to the Listserve, while thanking participants who already completed the survey. 
Due to the methodological limitations and Institutional Review Board guidelines it was impossible to determine the return rate. It was also not possible to determine exactly how many participants actually received the invitation to take the survey. Program directors were asked to send a return email to the researcher that contained the exact number of ACIs to whom the survey was sent. A total of 16 program directors replied to an initial email. The email had been forwarded to 107 ACIs, although many of these ACIs may not have been full-time university employed ACIs. This did not appear to affect the outcome as many of part-time or non-university employed ACIs did not complete the survey. One hundred and ninety-five out of a total of 212 participants reported that they were university employed ACIs.

The initial email to program directors prompted a return of 75 responses within the first week the majority of which (68) were received in the first three days. One week from the initial mailing the program directors were thanked for their participation and reminded to complete the survey. This time, 41 participants responded, 38 of which were received in the first three days. The beginning of the third week of the survey distribution, the call for participants was placed on the Yahoo Groups Athletic Training Education Listserve. This prompted 68 returns in one week, 64 of which came in the first 3 days. The last reminder was placed on the Listserve at the beginning of the fourth week and prompted 38 returns with the majority (24) once again received in the first three days. At this point the researcher began to receive negative feedback about the number of reminders that were posted. It was determined at this time that the number of responses was acceptable and that participants who were inclined to complete the survey, had ample time to do so. Research Questions 
It was expected that, from the information presented in the questionnaire, we will have learned much more about approved clinical instructors than has ever been known, especially in regards to perceptions of the state of clinical education. It was expected that the survey has produced a significant amount more of descriptive information about the state of clinical education as perceived by ACIs. The following research questions were addressed in the survey. Research Question 1- What are the demographic characteristics of this sample of ACIs? Research Question 2- What are the perceptions of the ACIs regarding the current process of clinical education since the implementation of the 2001 Proficiencies, Standards, and Guidelines (Part One of the survey)?

Research Question 3- What factors, identified in Part Two of the survey, facilitate or impede the clinical educational process?

Research Question 4- What are the immediate needs of practicing clinical education ACIs (Part Four of the survey)?

\section{Data Analyses}

Descriptive statistics were used to evaluate the data. Part One was analyzed by finding the mean for the sample for each question and this was placed and evaluated on the same scale. Part Two of the survey also used means to determine where the average score for the sample rested. Next the scores were listed from lowest facilitators to highest facilitators. Part Three identified the five most commonly identified factors that should be addressed for improvement of the clinical education process. These were listed from most to least commonly reported. Means and frequencies were used as indicated by the type of data that is obtained for the demographic questions. For example, age was evaluated by using the mean, and gender was evaluated by using frequencies. Question 52 (What is your official position at your institution?) 
was evaluated by first categorizing all responses and then by counting frequencies. One bivariate correlation was used in the data analysis strictly for clarification of the data. 


\section{CHAPTER 4}

Results

\section{Participants}

Two hundred and fourteen participants responded to the survey. Two surveys were excluded from this study due to significant missing data (more than half of the survey). All participants were given the opportunity to contact the researcher with questions regarding their eligibility to take the survey and their comments regarding the ease of the completion of the survey. Several participants responded with questions regarding eligibility, and two commented that the "factors" in Part Two were vague and confusing. Preliminary data inspection revealed that the remaining 212 surveys contained usable responses. For example, no more than $100 \%$ of any participant's job description was allotted to clinical education responsibilities. The low number of ineligible respondents, negative comments about the survey, and invalid responses to items suggests that the survey and its instructions were relatively easy to understand and complete. In addition, participants perceived the topic of the research to be important for the further development of the profession. This was evidenced by the participants' responses to the question, "Do you believe that this is an important topic for athletic training research?" A total of 212 participants responded to the question with $97 \%(n=205)$ identifying it as an important topic for athletic training research.

One hundred and five participants (49.5\%) learned about the survey via the program director, 78 (36.8\%) learned about the survey via the athletic training education Listserve and 27 (12.7\%) learned about the survey from some other source. Due to the distribution methodology, it was not possible to ascertain how many ACIs actually received the survey; therefore a definite response rate was not obtained. Although it was not possible to calculate the response rate, the 
sample was large $(N=212)$ and was diverse across demographic information gathered:

university settings (ex. Div I, II, III, and NAIA), gender, age, race, and years of experience.

\section{Demographics}

Demographic characteristics are presented in Tables One and Two. These demographics pertain to research question one and Part Four of the survey. Participants $(N=212)$ consisted of $113(53.3 \%)$ men and $97(45.8 \%)$ women with a mean age of 35.6 years $(S D=8.37)$. Ninety-two percent of participants were Caucasian $(n=196), 2.8 \%$ were Hispanic $(n=6), 1.4 \%$ were African American $(n=3), .5 \%$ were Asian American $(n=1)$, and 3\% did not respond. One hundred and fifty-one participants (71.2\%) reported a master's degree as their highest degree earned, while $37(17.5 \%)$ held earned doctorates, 20 (9.4\%) held bachelor's degrees, and 2\% did not respond. One hundred and ninety-five participants were ACIs at the university level, with 76 (35.8\%) at Division I schools, 41 (19.3\%) at Division II schools, 61 (28.8\%) at Division III schools, and $17(8 \%)$ at NAIA schools. Seventeen (8\%) reported serving as an ACI at a setting other than a school of higher education.

ACI titles. All participants $(N=212)$ provided their official title at their institution. Since there was great variability in the wording of their official titles ( 75 different titles were reported) 14 categories were formed to simplify output. Predominant titles noted were 'Program Director' ( $\mathrm{n}=49)$, 'Clinical Coordinator' $(n=32$,$) , and 'Head Athletic Trainer' (n=31)$. All responses can be seen in Table 1.

ACIs' position requirements. One hundred and ninety-seven participants reported mean hours per week involved in clinical education related duties as $11.73(S D=7.82)$. An average of $7.34(S D=6.37)$ years as a clinical instructor including years as an ACI was reported $(n=209)$, with responses ranging from one to 30 years. ACIs stated that they currently directly supervised 
a mean of $5.86(S D=6.34)$ students with a maximum of 45 and a minimum of zero. Participants estimated that eighteen percent $(S D=19.28 ; n=151)$ of their contractual agreements were devoted to clinical education activities with a minimum of $0 \%$ and a maximum of $80 \%$. Since the time contractually allotted for clinical education responsibilities ranged from $0-80 \%$ it is understandable why there was such a high standard deviation when compared to the mean $(S D=$ 19.28; $M=18.0)$. However, since there was an extremely high standard deviation reported regarding the question of contractual allowance, a correlation was performed to ensure that a relationship existed between hours spent per week in clinical education related activities and the

percentage of time contractually allowed. A moderate correlation was found $\left(r^{2}=.504, p<.001\right)$ indicating that these two items are directly positively related.

Sixty percent of respondents $(n=128)$ noted having no additional clinical education training other than the ACI training, while 84 participants (39.6\%) reported that they have had additional training.

Perceptions of the Clinical Education Process Since the 2001 Proficiencies, Standards, and Guidelines

All means in Part One represented agreement with the lowest mean being 3.70 and the highest mean 4.92. At least 205, and at most, 211 ACIs responded to all questions in Part One. Approved clinical instructors most strongly agreed with the statement, "I am satisfied with my ability to perform clinical education at this time" than any other statement $(M=4.92$; $S D=1.11$ ). ACIs were in agreement that the 2001 Proficiencies were an improvement to the clinical education process $(M=4.20 ; S D=1.10)$, but were slightly less certain that the addition of the proficiencies was feasible $(M=4.08 ; S D=.94)$. Furthermore, they were in agreement that the implementation of the proficiencies were a significant change to their practice $(M=4.36 ; S D$ 
$=1.37)$, and they were less certain that the process had become more manageable $(M=3.8 ; S D=$ 1.0). In fact, the lowest mean score $(M=3.70 ; S D=1.35)$ was in response to the statement, "I have enough time to properly implement Learning Over Time" and the second lowest mean $(M=$ 3.78; $S D=1.28$ ) was reported to the statement, "The important factors in clinical education are within my control." For more complete descriptive data on these factors, please see Table 4.

It is also necessary to note that although the means for all of the statements were on the "agree" side of the continuum, there were many who did not agree with the Part One statements, thus the high standard deviations reported in Part One.

Factors Perceived As Affecting the Clinical Education Process

Part Two of the survey (research question number two "What factors are more or less facilitating to the clinical education process?" identified 31 factors that had been reported to contribute to the clinical education process. The participants were asked to decide whether factors facilitated or impeded the clinical education process. A Likert scale ranging from -3 impedes to +3 facilitates was used. Mean scores were skewed toward facilitate with means ranging from .07 to 2.35 for the factors. The results of Part Two have been broken down into the top ten facilitators (see Table 5) and top ten impediments (see Table 6). The top ten (more facilitating) and bottom ten (less facilitating) factors were identified by their mean, and in addition standard deviation and range were given for these 20 factors.

Facilitators. The ten factors that had the highest means ranged from 1.77-2.35 with each factor ranging in individual responses from -3 to +3 . ACIs identified their relationships with their students as the biggest facilitator $(M=2.35 ; S D=.72)$. Participants also reported that their familiarity with their program's clinical education process $(M=2.09 ; S D=1.73)$, and their 
familiarity with the clinical education process in general $(M=2.00 ; S D=1.02)$ were key facilitators.

Lowest facilitators. Although all factors' means suggested an orientation towards facilitates, several factors received lower scores. The ten factors that had the lowest means ranged from $.07-1.07$ and all received individual scores that ranged from -3 to +3 . The lowest mean in Part Two was related to ease of documentation of Learning Over Time $(M=.07 ; S D=$ 1.86), and the second lowest mean was related to the ease of the documentation of the proficiencies $(M=.16 ; S D=1.86)$.

As mentioned above all factors' means were on the "facilitates" side, however, for the ten lowest "facilitators" at least $18 \%$ and at most $39 \%$ reported the factor to impede the process. It is also necessary to note that in all ten instances the most commonly selected "impedes" choice was "moderately impedes". There were two cases (factors 33 and 38) where the most frequently selected choice, of the available seven, was moderately impedes the process. This includes all of the "facilitates" choices.

\section{Most Important Factors to Be First Addressed}

In Part Three of the surveys, participants were asked to identify the five most important factors to address in order to improve the clinical education process. Each participant was given the opportunity to identify up to five factors from Part Two of the survey. All 31 factors were listed at least one time and a maximum of 96 times for a total of 900 valid responses. Several participants included some of the questions in Part One as their most important factors to first address. Since the first nine questions were not given as an option to choose as the top five factors to address, these choices were not used and officially labeled as missing. 
Ninety-six of $212(45.3 \%)$ participants identified "Ease of documentation of the proficiencies" as one of the top five most important factors to first address. The second most noted factor was, "Ease of documentation of Learning Over Time" identified by $37.7 \%(n=80)$ of the participants, followed by "Time allotted for my clinical education administration responsibilities" $(33.5 \%, n=71)$. The remaining top ten factors to first be addressed are listed in Table 7. 


\section{CHAPTER 5}

\section{DISCUSSION}

\section{Introduction}

ACIs are generally satisfied with the implementation of the 2001 Proficiency Standards and Guidelines. The ACIs that responded to the survey believed that in personal factors within their control generally facilitated the clinical education process, while those institutional factors (e.g. time, documentation, etc. facilitate less. The following pages will describe this phenomenon while also taking an in depth look at the survey that was designed specifically for this study.

\section{Survey Construction Analysis}

The survey appeared to be user friendly and a pertinent topic to gain 214 initial responses while only losing two participants due to attrition. Another finding in support of survey construction was that there were no instances where questions were answered with responses that were not possible. For example, there were no occurrences of participants reporting having 100 years of experience, nor any instances where participants responded to all questions with the same response (i.e. moderately agree for all questions). Additionally, by collecting demographic information at the end of the survey, and requiring many of these to be open-ended, it is likely that anyone who had answered randomly to the questions in parts one through three would not have taken the time to complete this demographic section. Since there were no missing demographic sections, other than the two that had significant missing data, it is assumed that responses were trustworthy.

The results from this study also suggest some initial support for content validity and reliability. As a group the participants answered questions regarding similar constructs consistently. For example, the construct Learning Over Time was addressed in several survey 
questions $(6,32,41)$, and the group as a whole responded to each of these items addressing this construct in a consistent manner. In this example, Learning Over Time was a significant issue in clinical education. Although the group answered questions about similar topics consistently, most questions in the survey received responses across all available choices. This variety in responses potentially indicates that the questions were specific and sensitive enough to highlight how the clinical education process affects individuals differently.

\section{Response Rate}

In this study, researchers were not able to determine a response rate; however, it is known that the study generated 212 usable surveys. This was determined to be a large enough sample to allow the researchers to evaluate the results and make recommendations for future research. It is also known that, although the researchers made an effort to invite the entire population to participate in this study, not all ACIs responded. Therefore, non-response bias must be addressed. It was impossible for the researcher in the current study to determine who did not respond to the survey, and why, several possibilities can be suggested. These possibilities include, but are not limited to, survey issuance at the end of the academic year, program directors that were responsible for initially distributing the survey may not have done so, and all internet survey limitations such as access to internet and preference of survey medium. While it is possible that these and other factors may have contributed to who did not respond to the survey (i.e. lack of time, low relevance of the topic to some ACIs), no data were available to support these ideas. In addition, it is unknown what the responses of those who did not participate would have been and this should be considered when interpreting the results. However, the demographic characteristics of the current sample were consistent with what is currently known of clinical instructors (CIs) and ATCs in general. Furthermore, there were no cases of a 
particular demographic missing from the response pool. For example, age, gender, and race were all consistent with previous findings. Therefore, it may be reasonable to assume that this sample was demographically representative of the ACI population and that no non-response bias was present. Sample Demographics

The sample that was gleaned from this study is demographically consistent with those reported in various other publications using university ATCs and CIs. The current study found participants to be $53.3 \%$ male and $45.8 \%$ female. The current representation of ATCs, as reported by the NATA, is $53.5 \%$ male and $47.0 \%$ female (NATA Salary Survey, 2005). Furthermore, Carr and Drummond (2002) reported that 58\% of the CIs that responded to their survey were male and $42 \%$ female. Again these figures are similar to the current study. Additionally, Carr and Drummond reported that the student population was $40 \%$ male and $60 \%$ female. The subtle shift found in the number of current professional females may reflect the filtration of Carr and Drummond's student sample to professional practice.

Other demographic factors that were included in this study were also consistent with previous literature. Carr and Drummond (2002) found the average age of clinical instructors to be 31.5 years while the present study found the average age of ACIs to be 35.6 years. The current study also found that $92 \%$ of participants were Caucasian while the average among ATCs is currently $86 \%$. Furthermore $2.8 \%$ reported to be Hispanic, 1.4\% African American, and $0.5 \%$ Asian American, while the current percentages among ATCs are 3.0\%, 2.0\%, and 3.0\% respectively (NATA.ORG). While this suggests that the sample was representative of the current ATC population, it also gives a preliminary understanding of who chooses to be, or can become, an ACI. It appears that being an ACI is not dependant upon gender, age, or race. However, this 
sample of ACIs, as well as current ATC trends, continues to demonstrate a lack of racial diversity when compared to the current US population breakdown (75\% Caucasian, 12.3\% Black or African American, 5.6\% other race, 3.6\% Asian, 2.4\% two or more races, $0.9 \%$ American Indian or Alaska Native) (http://factfinder.census.gov/servlet/SAFFFacts?_sse=on, Last accessed on $7 / 2 / 2005)$

As noted above, the sample appears representative of the ACI population. Therefore, it is assumed that other demographic information that has not been reported in previous studies is representative of the population. ACIs reported spending $11.73(S D=7.82)$ hours in clinical education related activities and stated that they spent approximately $18 \%$ of their contractual time involved in clinical education. According to the 2005 NATA Salary Survey, a similar population reported working an average of 49 hours per week. Based on these numbers (11.73 hours per week in clinical education, divided into a 49 hour work week) the average ACI spends $23.93 \%$ of their work week involved in clinical education while an average of only $18 \%$ is reportedly allotted for these responsibilities.

When the means of percentage of time contractually allotted to clinical education related activities and hours per week spent in these activities were compared, it demonstrated that ACIs spent almost $6 \%$ more time in these activities than is administratively dictated and allotted. This may indicate that the clinical education process requires more time than is being prearranged. The impact of this is unknown at present. However, it can be assumed that this discrepancy places additional stressors on the ACIs' workload. What is more, only $151(71.2 \%)$ participants were able to identify what percentage of their contractual obligations was devoted to clinical education activities. Because the ACIs are unable to identify how many hours per week they should spend in clinical education activities they may rely solely on the needs at the time. This 
may reflect an uncertainty of how much time is needed for the process not only by the ACI but also by administration. In turn, this may lead to ACIs feeling that they spend much more time in clinical education related tasks such as documentation, than they are compensated for, not to mention, time taken away from other duties (i.e. sport coverage, teaching, research). Although, hours per week devoted to the clinical education responsibilities has not been previously reported, it is likely that the time needed has increased since the implementation of the 2001 Proficiencies, Standards, and Guidelines. This may mainly be due to the increased amount of direct supervision of students and the more strenuous adherence to documentation standards.

Another finding of interest to the author is that there were 75 different titles reported. These were broken down into categories for the sake of simplification; however this may be important in demonstrating differences from program to program. The 2001 Proficiencies, Standards, and Guidelines provided general recommendations that must be followed for ATEPs to be in compliance. This disparity in titles may provide insight into how different institutions employ these Standards. The general nature of these proficiencies, Standards, and Guidelines gives individual institutions more freedom, but its effect on the congruency of programs must be studied further. For example, if there are 75 different titles that are acceptable for ACIs in ATEPs, what other Standards are met with such variability?

\section{Perceptions of the Athletic Training Process}

Part one of the survey was designed to gain a better understanding of how ACIs currently perceive the athletic training process since the implementation of the 2001 Proficiencies, Standards, and Guidelines. All questions in part one received at least 205 responses out of the possible total of 212. Every question received a wide range of responses spanning all available choice options (1 strongly disagree -6 strongly agree). This may indicate that the clinical 
education process affects ACIs differently and also perceived experience varies between institutions. Although there were responses across the entire available range of choices, the standard deviations around the mean were relatively low; .94 - 1.37. This demonstrated that there was a certain level of agreement among the sample.

In general, it appears that ACIs were satisfied with their ability to perform clinical education at this time. This was evidenced by ACIs more strongly agreeing with this statement than any other Part One statement $(M=4.92 ; \mathrm{SD}=1.11)$. This finding is also supported by the fact that the second highest mean was related to the statement, "I am satisfied with my institution's contributions to the clinical education process (They understand and support)". It is important to note that these first two statements represent a more global view of how the clinical education process is perceived by ACIs. However, when questioned about the specifics of the clinical education process, ACIs demonstrated agreement but to a lesser degree for those items.

There were three statements that received less than a $4.0(3.70,3.78,3.80$, see Table 2$)$. This indicates that the average response to these statements was less than slightly agree. For example, the lowest mean was related to the statement, "I have enough time to properly implement Learning Over Time" $(M=3.70)$ and the second lowest mean corresponded with, "The important factors affecting the clinical education process are within my control" $(M=$ 3.78).

Although ACIs generally feel satisfied in their ability to perform clinical education at the time of this survey, they reported that the implementation of the 2001 Proficiencies, Standards, and Guidelines were a significant change to their practice $(M=4.3 ; S D=1.37)$. However, this is the item with the greatest standard deviation in Part One. This may be because several programs were in compliance with the 2001 Proficiencies Standards well before the mandatory 2003 begin 
date. While many reported that the process was feasible $(M=4.0 ; S D=.94)$, ACIs were less confident that the process is becoming more manageable $(M=3.80 ; S D=1.20)$. This may be a concern since ACIs have now had at least two years to adapt to the new clinical education policies.

Factors Influencing Clinical Education

Part Two of the survey contained 31 factors that have been found to influence the clinical education process. Respondents were asked to decide whether these factors generally impeded or facilitated the clinical education process. As was the case in Part One of the survey, all mean response scores were skewed to one side of the continuum. All factors' means were reported to be facilitators. However, several factors were reported to be stronger facilitators than others. Table 3 represents the ten factors with the highest means representing a trend towards the belief in the factors being facilitators. It is very interesting to note that the top ten facilitators were all personal items such as, "My relationship with the other ACIs" and, "In general, my relationship with the students." This may indicate that ACIs feel as though they have maximized the ability to change factors represented in the items that are directly within their control. It may be interesting to learn how ACIs learn to control these factors. Not only are the top ten facilitators personal items, but many are referring to social support from peers. Therefore it is possible that relationships are generally seen as facilitators because of how they identify with each other and share common challenges. Future research may seek to examine how these factors facilitate the process, and also how these factors can become greater facilitators to the clinical education process.

In contrast to these findings, the factors that received the lowest facilitation scores are factors that may be labeled as institutional. Many ACIs may not feel that these items are within 
their control. This theory is reinforced by the relatively low means for the Part One question, "The important factors in clinical education are within my control." Along with the institutional nature of the factors identified as major impediments, most of the lowest scores related to time related tasks such as ease of documentation of the proficiencies and documentation of Learning Over Time. These two factors were most likely the most significant changes that occurred as a direct result of instituting the 2001 Proficiencies, Standards, and Guidelines. Future research should further explore the lowest facilitators to the clinical education process. In addition, researchers may wish to explore the possible reasons that there was such disparity between respondents for the "lowest facilitators". This may be especially interesting for the factors in which the mode was "moderately impedes" the clinical education process. As a result of this exploration, recommendations regarding how to improve these factors should be sought. For example, further exploration regarding the difficulties with documenting the proficiencies may reveal that ACIs do not have enough training to be efficient at this process. Further training may make this process less cumbersome. Technological advances may make it possible to document clinical placement learning as it occurs, perhaps with the use of PDA's or pocket PC's. It may be possible to create and market programs for these devices to make this documentation easier. Most Important Factors to First Address.

The purpose of Part Three was to identify the factors from Part Two that would be most beneficial to first address for improvement of the clinical education process. It would at first glance appear that the top five impediments would automatically be the same factors that would be most beneficial to address, but there may be circumstances that certain important factors may be more feasible to address than other factors. In this study the factors to first address were five of the six lowest facilitators to the clinical education process. The top five factors that would be 
most beneficial to first address, all share one common thread: time. Time is a factor that is often cited as a barrier to increased performance.

Future research may wish to examine how time is spent in clinical education duties, and whether or not it is possible to increase the efficiency of time spent. Continuing education courses developed by ACIs relating directly to how to improve these factors should be pursued. It may be that further education of ACIs in the area of clinical education may prove to make the most significant improvements to the clinical education process. This position may be reinforced by the fact that $60.5 \%$ of ACIs have no clinical education training other than the ACI course. Further evidence that continuing education may be part of the solution to clinical education concerns is offered considering time and support of clinical education needs were also in the lowest ten facilitators (See Table 4). It is the belief of this researcher, secondary to the positive responses on the global indicators of how ACIs feel about the process in general, that small changes aimed at decreasing the time consuming nature of these factors may prove to be significant steps towards improving the clinical education process.

\section{Limitations}

It is necessary to note limitations to this study. First, it should be noted that elements of the discussion addressed the "lowest facilitators," and not the greatest impediments. While this may only be a question of semantics, it seemed necessary in order not to mislead the reader. The only reason that this was changed was that there were no factors that were identified as general impediments to the process. This however, this does not mean that the lowest facilitators are not significant to note, and therefore were discussed thoroughly.

The following two sections have been broken down into additional notes for practice and further recommendations for future research. The notes for practice are intended to provide 
practitioners with methods of improving difficult aspects of the clinical education process, while the recommendations for future research are intended to guide researchers in subsequent research.

\section{Additional Notes for Practice}

This study is the one study available that has attempted to understand how athletic training clinical instructors view the clinical education process, and more specifically since the implementation of the 2001 Proficiencies, Standards, and Guidelines. It is the belief of this researcher that the 2001 Proficiencies, Standards, and Guidelines have improved the clinical education process, and hopefully improved the quality of the process for students by relatively standardizing the process. This standardization was aimed at ensuring that all programs meet the established guidelines. However, there is a lot of room of individual variance between institutions regarding how these guidelines are met.

It is also the belief of this researcher that there should be post-implementation research, thus evaluation, after any significant changes to professional practice. If there is not this followup, then there is the possibility that the people who are directly affected by such changes may feel as though they are not a primary concern of the policy makers. Policy makers will be able to make more beneficial changes when previous changes are evaluated and the major stakeholders feel they have input.

ACIs are a cornerstone of any athletic training educational program. Students have acknowledged that clinical instructors have the potential to affect the student experience in clinical education (Anderson, Larson, \& Luebe, 1997; and Curtis, Helion, \& Domsohn, 1998). The elements of this study should contribute to a better understanding of how the average 
clinical instructor feels about the process since the implementation of the 2001 Proficiencies, Standards, and Guidelines and also about what factors affect the clinical education process.

The results indicate that the factors that were least facilitating to the clinical education process were factors related to the administrative details of the ATEPs such as time and administrative support. These results may demonstrate a need to reanalyze the work expectations related to clinical education of ACIs working within their programs. Administrators should determine the feasibility of job descriptions of related to expectations of the ACIs within the ATEPs. A large number of ACIs did not know how much of their contractual agreement is allotted to clinical education $(n=61)$. It would be helpful for administrators provide clear expectations for time allotted for clinical education responsibilities and directly relate these to compensatory rewards.

The results of this study also indicate that the implementation of the 2001 Proficiencies, Standards, and Guidelines was perceived to be a change to the average ACIs professional practice, but are perceived to have improved the clinical education process although there are general concerns regarding certain aspects of the implementation.

Further recommendations for practice must also be aimed at decreasing the concern with time related issues. While some time related issues may be impossible to improve (e.g. number of students supervised per semester) due to a lack of available funding for new hires, some may be very feasible. For example PDA or Pocket PC software created specifically for athletic training clinical education may be used at the clinical sites therefore decreasing the amount of documentation that occurs after hours. This immediate documentation should also improve the accuracy of the documentation as well as improve the attractiveness of on-site clinical teaching. This software could also improve the clinical education process by providing structure to the on- 
site teaching. More structured on-site clinical education learning has been sited as a necessity in the literature especially when considering that athletic training students spend 59 percent of their on-site clinical education un-engaged (Miller \& Berry, 2002). This time spent waiting can be used more efficiently, by teaching and documenting this teaching through the use of PDAs and Pocket PCs.

Along with these innovations, practitioners may benefit from education in these areas of particular concern such as documentation and administration. Continuing education should be designed to improve these skills. The two factors that related to continuing education (Q 12, "Time allotted to me for my educational endeavors", $M=.34 ; S D=1.69$, and Q 35 , "Institutional support with clinical education continuing education needs", $\mathrm{M}=.99 ; S D=1.64$ ) were regarded as low facilitators. When these findings are combined with the fact that only 39.4 percent of this sample of ACIs reported having any other clinical education training than the ACI course, this may indicate that more continuing education should focus on clinical education teaching methods beyond what is taught in the six hour ACI training course. More continuing education should be designed to teach ACIs more about how to maximize learning in the clinical education setting.

Further Recommendations for Future Research

Many recommendations for future research have been stated throughout this discussion. The following paragraphs will describe additional thoughts for future research. Although this is not a definitive list, these recommendations should provide a solid base from which researchers can frame future research.

The findings of this study may indicate that ACIs believe that in general they are satisfied with their ability to contribute to the process, but when asked about the specifics they were less 
confident about the feasibility of the process as it currently stands. Many times the easiest way to determine the functionality of a process that involves the dynamics and interrelationships among people is to ask the people involved. It is an encouraging finding that the general statements about the clinical education process are very positive. This may indicate that there is no specific need for global change in this area. However, certain variables consistently emerged at the forefront of discussion. As stated in chapter one, this study was conceived after talking with clinical educators about the process and the new changes in the process. The informal consensus was that although the process seemed to have been improved by the significant changes contained in the 2001 Proficiencies, Standards, and Guidelines, the process had become more time consuming and sometimes less enjoyable. The findings of this study confirm that those beliefs are shared with many other clinical instructors at other institutions.

The timing of this study was crucial in that it occurred more than two years since the changes have been in place. It would have been interesting if a similar study had been performed prior to the implementation of the new proficiencies, Standards, and Guidelines. As stated earlier the results of this study may have been skewed because some programs may have been in compliance with these Standards for years, and some my have been in compliance for months prior to the mandatory implementation in 2003. It may be interesting to compare the results and findings of the ACIs who said that it has been a significant change in their practice with those who said that it had not.

Follow-up analyses that may be explored in the future will be performed to determine whether certain factors correlate with each other, or with items from other parts of the survey. For example it will be of interest to determine whether factors such as "My enjoyment with the clinical education process" and "Number of students supervised this term" are correlated with 
each other. It may be reasonable to run correlations between "Number of students supervised this term: with most ability to contribute to the clinical education process at this time". It seems logical to predict that the factors in Part Two that are related to time concerns should correlate with questions from other Parts of the survey, such as the Part One question "The clinical education process is becoming more manageable." Correlations should be performed between the least facilitating factors (institutional factors) and satisfaction with their institution's contribution to the clinical education process. It will also be interesting to determine whether or not there is a difference in satisfaction to contribute to the process and primary academic versus clinical roles. For example is there a difference between Program Directors and Clinical Coordinators and all other ACIs survey in this study. The high number of responses for seemingly academic positions (ie. Program Directors and Clinical Coordinators) may have been enough to skew the responses to a general positive finding. While primary academic positions usually carry much responsibility, direct student supervision is generally not a primary responsibility; therefore these respondents may offer a different viewpoint from the other respondents. Exploratory analyses of this survey to determine whether or not relationships can be identified in addition to those that were stated in the purpose of this study. For example, follow-up analyses may include further exploration of the individual questions that received the highest and lower scores. For example, "Does experience affect who is satisfied with their ability to perform the clinical education process?" In depth evaluation of these findings will be labor intensive, but there is the potential for a more thorough understanding of the clinical education process. Future research may also choose to use more specific sub-populations, and/or alternative methods of research design such as qualitative assessments. 
In conclusion, ACIs are generally satisfied with the implementation of the 2001 Proficiency, Standards, and Guidelines. The ACIs that responded to the survey believed that in personal factors within their control generally facilitated the clinical education process, while those institutional factors (e.g. time, documentation, etc. facilitate less. Possibly the most important finding of this study is that although the implementation of the 2001 Proficiencies, Standards, and Guidelines was met with significant resistance from the ground level (practitioners), ACIs, currently, feel reasonably satisfied with their ability to perform in the clinical education process. This is crucial in that the overall findings of this study were so positive especially when considering the top down nature of these changes to the Proficiencies, Standards, and Guidelines. In following surveys, responses from the same programs should be collected in order to identify "model" programs. These model programs can be studied to determine what makes ACIs perceptions within these programs more positive. The researchers are hopeful that this study will be the first of many studies aimed at improving the clinical education process through research involving the major stakeholders. 


\section{References}

Accreditation Standards: Athletic Training. (2001). Retrieved on January 23, 2004, from http://www.caahep.org/documents/AthleticTraining2001.doc.

Anderson, M., Larson, G. \& Luebe, J. (1997). Student and supervision perceptions of the quality of supervision in athletic training education. Journal of Athletic Training, 32, 328-332.

Beauchamp, L., Darst, P., \& Thompson, L. (1990). Academic learning time as an indication of quality high school physical education. Journal of Physical Education, Recreation, and Dance, 61, 92-95.

Blue, A., Stratton, T., Plymale, E., DeGnore, L, Schwartz, R., \& Sloan, D. (1998). The effectiveness of the structured clinical instruction module. American Journal of Surgery, $176,67-70$.

Bok, D. (1992). Reclaiming the public trust. Change, 24, 13-19.

Brown, S. (1981). Faculty and student perceptions of effective clinical teachers. Journal of Nursing Education. 20, 4-15.

Carr, D.,\& Drummond, J. (2002). Collaboration between athletic training clinical and classroom instructors. Journal of Athletic Training, 37, s182-s188.

Curtis, N., Helion, J., \& Domsohn, M. (1998). Student athletic trainer, perceptions of clinical supervisor behaviors: A critical incident study. Journal of Athletic Training, 33, 249253.

Davis, C., \& Misasi, S. 2001. Student athletic trainer vs. athletic training student: Get over it and get on with it! NATA News, August, 16.

Delforge, G., \& Behnke, R. (1999). The history and evolution of athletic training education in the United States. Journal of Athletic Training, 34, 53-61. 
Dillman, D. (2000). Mail and internet surveys. The tailored design method. $2^{\text {nd }}$ Edition. John Wiley Co: New York.

Dillman, D., Tortora, D., \& Bowker, D. (1999) Principles for Constructing Web Surveys. SESRC Technical Report 98-50, Pullman, Washington.

Duncan, K., \& Wright, K. (1992). A national survey of athletic trainer roles and responsibilities I the allied clinical setting. Journal of Athletic Training, 27, 311-316.

Dunlevy, C., \& Wolf, K. (1992). Perceived differences in the importance and frequency of practice of teaching behaviors. Journal of Allied Health, Summer, 175-183.

Emery, M. (1984). Effectiveness of the clinical instructor: students' perspective. Physical Therapy, 64, 1079-1083.

Ende, J. (1983). Feedback in medical clinical education. Journal of the American Medical Association, 25, 777-781.

Fong, C., \& McCauley, G. (1993). Measuring the nursing, teaching, and interpersonal effectiveness of clinical instructors. Journal of Nursing Education, 32, 325-327.

Foster, D, \& Leslie, D. (1992). Clinical teaching roles of athletic trainers. Journal of Athletic Training, 27, 298-302.

Frisch, N., \& Coscarelli, W. (1986). Systematic instructional strategies in clinical teaching: outcomes in student charting. Nurse Educator, 11, 29-32.

Garndner, G., \& Harrelson, G. (2002). Situational Teaching: Meeting the needs of evolving learners. Athletic Therapy Today, 7(5), 18-22.

Gjerde, C. \& Coble, R. (1982). Resident and faculty perceptions of effective clinical teaching in family practice. Journal of Family Practice, 14, 323-327. 
Grace, P. (1999). Milestones in athletic trainer certification. Journal of Athletic Training, 34, 285-291.

Harrelson, G., \& Gallaspy, J. (1997). Predictors of success on the NATABOC certification exam. Journal of Athletic Training, 32, 323-328.

Harrelson, G., \& Leaver-Dunn, D. (2002). Using the experiential learning cycle in clinical instruction. Athletic Therapy Today, 7(5), 23-27.

Hertel, J., West, T., Buckley, W., \& Denegar, C. (2001). Educational history, employment characteristics, and desired competencies of doctoral-educated athletic trainers. Journal of Athletic Training, 36, 49-57.

Hutchinson A. \& Johnston L. (2004). Bridging the divide: a survey of nurses' opinions regarding barriers to, and facilitators of, research utilization in the practice setting. Journal of Clinical Nursing, 13, 304-315.

Irby, D. (1986). Clinical teaching and the clinical teacher. Journal of Medical Education, 61, 3545.

Irby, D., Ramsey, P, Gilmore, G., \& Schaad, D. (1991). Characteristics of effective clinical teachers of ambulatory care medicine. Academic Medicine, 66, 54-55.

Jarski, R., Kulig, K., \& Olson, R. (1990). Clinical teaching in physical therapy: student and teacher perceptions. Physical Therapy, 70, 173-178.

Jarvis, P. (1983). Professional Education. Beckenham, UK, Croom Helm.

Kennedy, M. (1999). Making an Impact. American School \& University, 72, 16-26.

Kennedy, M. (2002). Creating ideal facilities: here are 10 ways a school can provide an effective learning environment. American School \& University, 74, 30-33.

Knight, K. (1990). Clinical experiences in athletic training. Champaign, IL, Human Kinetics. 
Koehneke, P. (2003, June). JRC-AT Update (leaving CAAHEP). Presented at the National Athletic Trainer's Association Meeting, Baltimore, Maryland.

Konin, J., Amato, H., \& Brader, H. (2002). Incorporating the Renne test into the learning-overtime model. Athletic Therapy Today, 7, 12-17.

Ladyshewsky, R., Barrie, S., \& Drake, V. (1998). A comparison of productivity and learning outcomes in individual and cooperative physical therapy clinical education models. Physical Therapy, 78, 1288-1298.

Lauber, C., Toth, P., Leary, P., Martin, D., \& Killian, C. (2003). Program directors' and clinical instructors' perceptions of important clinical-instructor behavior categories in the delivery of athletic training clinical instruction. Journal of Athletic Training, 38, 336-341.

Laurent, T., \& Weidner, T. (2001). Clinical instructors' and student athletic trainers' perceptions of helpful clinical instructor characteristics. Journal of Athletic Training, 36, 58-61.

Laurent, T., \& Weidner, T. (2002). Clinical-education-setting standards are helpful in the professional preparation of employed, entry-level certified athletic trainers. Journal of Athletic Training, 37, s248-s254.

Massie, B. (2000). Athletic training Education: Are we adequately preparing our students to practice athletic training? [dissertation]. Cincinnati, $\mathrm{OH}$ : University of Cincinnati.

Metcalf, M. (2000). Changing the rules. College Plan Manage, 3, 52-54.

Miller, M., \& Berry, D. (2002). An assessment of athletic training students' clinical-placement hours. Journal of Athletic Training, 37, s229-s235.

Morgan, J., \& Knox, J. (1987). Characteristics of 'best' and 'worst' clinical teachers as perceived by university nursing faculty and students. Journal of Advanced Nursing, 12, 331-337. 
National Athletic Trainers' Association Member Statistics. (2005). Accessed July 7, 2005, https/www.nata.org/members1/statistics.

National Athletic Trainers' Association Salary Survey. (2005). Accessed July 7, 2005, https://www.nata.org/members1/salarysurvey2005/results.cfm

Nehring, V. (1990). Nursing clinical teacher effectiveness inventory: a replication study of the characteristics of 'best' and 'worst' clinical teachers as perceived be nursing faculty and students. Journal of Advanced Nursing, 15, 934-940.

Perrin, D., \& Lephart, S. (1988). Role of the NATA curriculum director as clinician and educator. Journal of Athletic Training, 23, 41-43.

Platt-Meyer, L. (2002a). Leadership characteristics as significant predicators of clinical-teaching effectiveness. Athletic Therapy Today, 7, 34-39.

Platt-Meyer, L. (2002b). Athletic training clinical instructors as situational leaders. Journal of Athletic Training. 37, s261-265.

Polifroni, E., Packard, S., Shah, H., \& Macavoy, S. (1995). Activities and interactions of baccalaureate nursing students in clinical practice. Journal of Professional Nursing, 11, $161-169$.

Seaton, J. (1978). Clinical faculty issues. In: Ford CW; Clinical education for the allied health professions. St. Louis, MO: Mosby. 159.

Siedentop, D. (1991). Developing teaching skills in physical education. $3^{\text {rd }}$ ed. Mountainview, CA: Mayfield Publishing Co.

Sloan, D., Donnely, M., \& Plymale, M. (1997). Improving residents' clinical skills with theh structured clinical instruction model for breast cancer: results of a multi-institutional study. Breast Cancer Education Working Group, Surgery, 122, 324-333. 
Slotnik, H. (1996). How doctors learn: the role of clinical problems across the medical school-topractice continuum. Academic Medicine, 71, 28-34.

Starkey, C. (2002). Curriculum development. Journal of Athletic Training, 37, s-180-181.

Staurowsky, E., \& Scriber, K. (1998). An analysis of selected factors that affect the work lives of athletic trainers employed in accredited educational programs. Journal of Athletic Training, 33, 244-248.

Stemmans, C., \& Gangstead, S. (2000). A psychometric investigation of the clinical instruction analysis tool- athletic training II. Perceptual and Motor Skills, 91, 1040-1044.

Swann, E. (2002). Communicating effectively as a clinical instructor. Athletic Therapy Today, 7, 28-33.

Swan, E., \& Walker, S. (2001). Interpersonal Communications of the athletic training clinical instructor [abstract]. Journal of Athletic Training, 36, s48.

Tinto, V. (1997). Classrooms as communities: exploring the educational character of student persistence. Journal of Higher Education, 68, 599-624.

Toburen, K., (2002), Commentary. Journal of Athletic Training, 37, s220-221.

Turocy, P. (2002). Overview of athletic training education research publications. Journal of Athletic Training, 37, p. s162-s167.

Turocy, P., Comfort, R., Perrin, D., \& Gieck, J. (2000). Clinical experiences are not predictive of outcomes on the NATABOC examination. Journal of Athletic Training, 35, 70-75

U.S. Census Information. (2004). Last accessed on 7/2/2005. http://factfinder.census.gov/servlet/SAFFFacts?_sse=on

Villafuete, A. (1996). Structured clinical preparation time for culturally diverse baccalaureate nursing students. International Journal of Nursing Students, 33, 161-170. 
Weidner, T. (1997). The athletic therapist as clinical instructor. Athletic Therapy Today, 2, 49.

Weidner, T., \& Henning, J. (2002a). Being an effective athletic training clinical instructor. Athletic Therapy Today, 7, 6-11.

Weidner, T, \& Henning, J. (2002b). Historical perspective on athletic training clinical education. Journal of Athletic Training, 37, s222-s228.

Weidner, T., \& Laurent, T. (2001). Selection and evaluation guidelines for athletic training clinical education settings. Journal of Athletic Training, 36, 62-67.

Weidner, T., Pipkin, J. (2002). Clinical supervision of athletic training students at colleges and universities needs improvement. Journal of Athletic Training, 37, s-241-247.

Weidner, T., Trethewy, J., August, J. (1997). Learning clinical skills in athletic therapy. Athletic Therapy Today, 2(5), 43-49.

Winston, G. (1992). Hostility maximumization and the public trust. Change, 24, 20-27. 


\section{APPENDICIES \\ Appendix A \\ Cover Letter for Pilot \#1

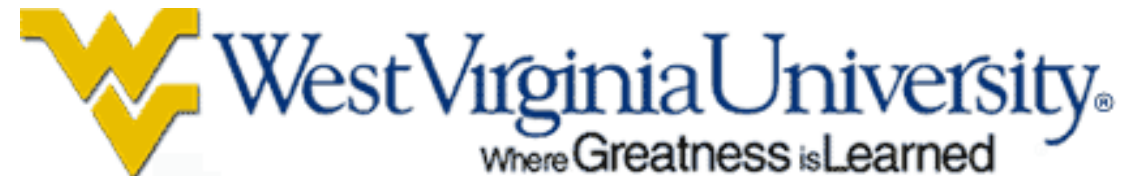

Alan Nasypany Jr. MEd, ATC Doctoral Student West Virginia University

Dear ATC,

I am currently designing a survey to attempt to describe current perceptions of Approved Clinical Instructors (ACIs) regarding clinical education. I have identified factors that can potentially impede or facilitate clinical education. I have selected a group of professionals in athletic training and more specifically those who have been active in researching clinical education to help me create a relatively comprehensive list of the factors that significantly affect the clinical education process. The study is being conducted as part of a doctoral dissertation.

This survey will take approximately 5-10 minutes to complete. If you choose to participate in this process, I will ask you to identify any factors that are not currently on the list that you feel are important, or factors that are on the list that you do not feel are important. I believe that your help with this process will significantly increase the validity of my final instrument. Your participation with this is completely voluntary; your status of employment will in no way be compromised should you not wish to participate.

Your response to this survey will remain anonymous. To ensure this, I ask that you return your additions as a word document to the unbiased third party listed to below. Once your reply is received, Ms. Schmidt will forward the additions to me with no identifying information on it.

If you have any questions about the study please feel free to contact me, Alan Nasypany Jr., at 304296 7723. For your rights as a research participant, you may call the Executive Secretary of the WVU Research Compliance Office at 3042937073.

Please return additions to: $\underline{\text { schmidtb@,healthworksrf.com }}$ 
I thank you very much for you time and participation with this important project.

Sincerely,

Alan Nasypany Jr. MEd ATC

Doctoral Student 
Appendix B

Participants' Cover letter for Pilot \#2

WWestVirginiaUniversity。

Alan Nasypany Jr. MEd, ATC Doctoral Student

West Virginia University

Dear ATC,

The purpose of the following two page survey is to describe the current state of the clinical education process. The study is being conducted as part of a doctoral dissertation.

The survey will take only 10-15 minutes to complete. It is important that you respond honestly and as accurately as possible. Your participation with this is completely voluntary and your employment status will not be affected if you choose not to participate. You do not have to answer every question, but responding as completely as possible will provide us with valuable information. The information that we gather will be used to learn current attitudes and feelings regarding the clinical education process. I would also like you to note any questions or concerns that you may have regarding the survey.

I would like you to: 1) Take the survey; 2) Note the time it takes you to take the survey; 3) Note any confusing questions; 3) Add any pertinent comments or questions.

Your response to this survey will remain confidential. Once your survey is received it will be entered into a database without any identifying information on it.

If you have any questions about the study please feel free to contact me, Alan Nasypany Jr., at 304296 7723. For your rights as a research participant, you may call the Executive Secretary of the WVU Research Compliance Office at 3042937073.

I thank you very much for you time and participation with this important project.

Sincerely, 
Appendix C

Program Director Cover Letter for Pilot \#2

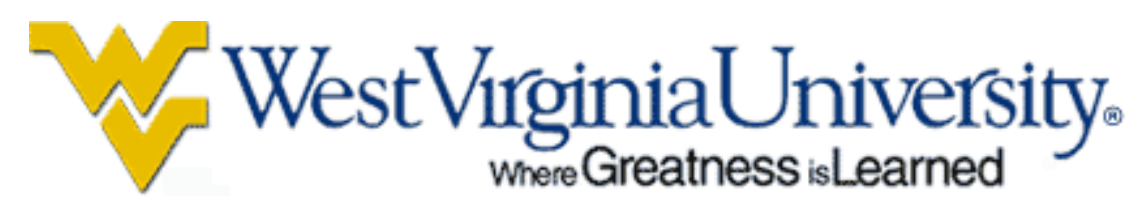

March 21, 2005

Dear Program Director,

I would like to ask your assistance in distributing my survey to approved clinical instructors (ACI's) currently working in approved athletic training educational programs (ATEP's). The purpose of this survey is to describe the current state of the clinical education process in ATEP's as perceived by the ACI's. Specific purposes of this survey are to 1) Identify ACI's perceptions of the current state of the clinical education process; 2) Identify factors of the clinical education process that either facilitate or impede this process; 3) Identify those factors that are perceived as the most beneficial to address to improve the clinical education process; and 4) provide demographic information on all ACI's currently attached to ATEP's.

I ask that you forward the web-link to all ACI's currently involved in your ATEP. You may forward this email if you think it will be beneficial to do so. I also ask that you complete this 510 minute survey, and that you encourage all ACI's to complete this, as it will provide valuable information about the clinical education process as perceived by the major stakeholders; the ACI's.

Institutional Review Board consent has been attained and all relative information is provided via the web-link. You may view the survey at any time by accessing the web-link. All responses are voluntary, and will remain anonymous. All participants may reserve the right not to participate in this study, and your employment status will not be affected whether or not you choose to participate. 
Thank you in advance for assisting me to better understand the current state of the clinical education process nationwide.

If you have any questions regarding this process please feel free to contact me at amnasypany@yahoo.com.

Sincerely,

Alan Nasypany Jr. ATC 
Appendix D

Program Director Cover Letter for the Final Survey

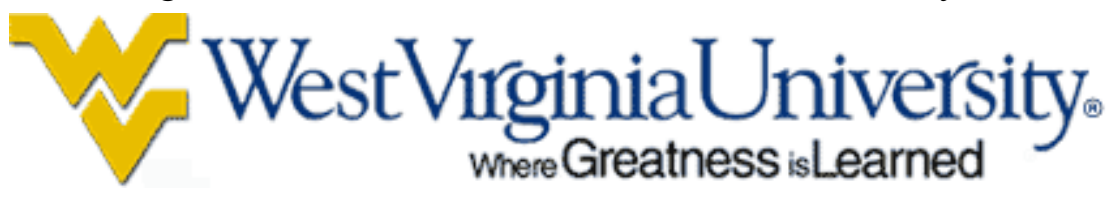

April 11, 2005

Dear Program Director,

Hello, my name is Alan Nasypany Jr. I have been an ATC for six years and I am currently pursuing a doctorate in teacher education at West Virginia University. I am conducting research in clinical education to better understand the factors that facilitate or impede this process. I intend to publish the results of this survey, with the intention of contributing to the clinical education process by gaining more insight to the process, as perceived by the ACls.

I would like to ask your assistance in distributing my survey to approved clinical instructors (ACl's) currently working in approved athletic training educational programs (ATEP's). The purpose of this survey is to describe the current state of the clinical education process in ATEP's as perceived by the ACl's. Specific purposes of this survey are to 1) Identify ACl's perceptions of the clinical education process since the implementation of the 2001 Standards and Guidelines; 2) Identify factors of the clinical education process that either facilitate or impede this process; 3 ) Identify those factors that are perceived as the most beneficial to address to improve the clinical education process; and 4) provide demographic information on all ACl's currently involved in ATEP's.

I ask that you forward the web-link to all full-time, university employed ACl's currently involved in your ATEP. You may forward this email if you think it will be beneficial to do so. I also ask that you complete this 5-10 minute survey, and that you encourage all ACl's to complete this, as it will provide valuable information about the clinical education process as perceived by the major stakeholders; the ACl's. 
I also ask that you reply to this email with the number of ACls that you have forwarded the link to. This will be crucial to obtaining an accurate response rate and therefore aid in determining our confidence in generalizing the results to the population of ACl's.

Institutional Review Board approval has been attained and all relevant information is provided via the web-link. You may view the survey at any time by accessing the web-link. All responses are voluntary, and will remain anonymous. All participants may reserve the right not to participate in this study, and your employment status will not be affected whether or not you choose to participate.

The link: http://www.wvu.edu/ physed/nasypany/

Thank you in advance for assisting me to better understand the current state of the clinical education process nationwide.

If you have any questions regarding this process please feel free to contact me at amnasypany@yahoo.com. I have also attached a word document with my signature.

Sincerely,

Alan Nasypany Jr. ATC

Doctoral Candidate 


\section{Appendix E}

\section{Survey For Pilot Study \# 1}

* Participants will be asked to identify factors that impede or facilitate the clinical education process. Please add any items to this list that you believe I have omitted. You can either add them to the end of the table, or you can simply list them at the end. If you feel any items on the list are unclear or unnecessary please identify them. This is how the list will be presented in the survey.

Factors that affect the delivery of clinical education. Please answer this section according to how these items affect you at this point in time. Circle the best answer.

Impedes Neutral Facilitates

$\begin{array}{lllllllll}\text { 9. My familiarity with the clinical } & -3 & -2 & -1 & 0 & 1 & 2 & 3 & \text { N/A }\end{array}$ education process

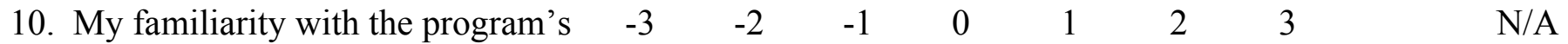
individual workings

$\begin{array}{llllllllll}\text { 11. Time allotted to educational } & -3 & -2 & -1 & 0 & 1 & 2 & 3 & \text { N/A }\end{array}$ endeavors

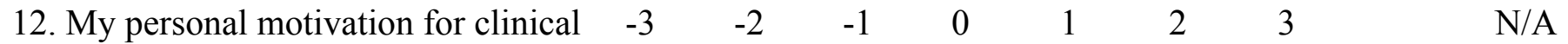
education

13. My teaching experience

14. My formal teacher training

15. My current teaching confidence

16. My job description

17. My enjoyment of the C.E. process

18. Department support (emotional)

$\begin{array}{lll}-3 & -2 & -1\end{array}$

$\begin{array}{lll}-3 & -2 & -1\end{array}$

$-3$

$$
-3
$$

$-3$

$-3$




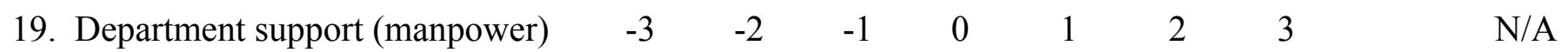

20. Number of students supervised this $\begin{array}{rllllllll} & -3 & -2 & -1 & 0 & 1 & 2 & 3 & \text { N/A }\end{array}$ semester

$\begin{array}{lllllllll}\text { 21. Type of setting as it relates to } & -3 & -2 & -1 & 0 & 1 & 2 & 3 & \text { N/A }\end{array}$ functionality (ex. training room, practice, laboratory, game, clinic, etc.)

22. My sport responsibilities (coverage)

23. Type of sport

24. Facilities (location, size, functionality)

25. My relationship with the students $\quad \begin{array}{llllllll}-3 & -2 & -1 & 0 & 1 & 2 & 3\end{array}$

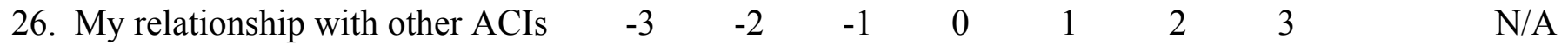

$\begin{array}{lllllllll}\text { 27. My relationships with supervisors } & -3 & -2 & -1 & 0 & 1 & 2 & 3 & \text { N/A }\end{array}$

28. Ease of documentation of the $\quad \begin{array}{lllllllll} & -3 & -2 & -1 & 0 & 1 & 2 & 3 & \text { N/A }\end{array}$ proficiencies

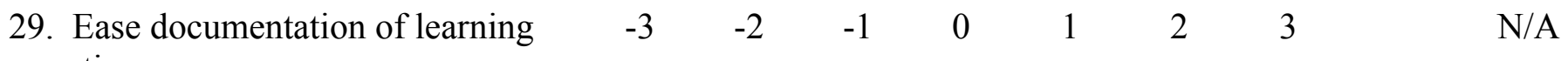
over time

$\begin{array}{lllllllll}\text { 30. My satisfaction with job } & -3 & -2 & -1 & 0 & 1 & 2 & 3 & \text { N/A }\end{array}$

$\begin{array}{lllllllll}\text { 31. Administrative support with } & -3 & -2 & -1 & 0 & 1 & 2 & 3 & \text { N/A }\end{array}$ clinical education continuing education needs.

32. My leadership skills

$\begin{array}{lllllll}-3 & -2 & -1 & 0 & 1 & 2 & 3\end{array}$

N/A

Other factors may be added to the table, or listed below Thank you, Alan Nasypany Jr. 
Appendix F

Survey For Pilot \#2

Part One: This section contains questions regarding your feelings of the clinical education process at this time. Please circle the best answer that most appropriately describes your current attitudes.

$\begin{array}{cccccc}S D & \text { MD } & \text { D } & \text { A } & \text { MA } & \text { SA } \\ 1 & 2 & 3 & 4 & 5 & 6 \\ \text { Strongly } & \text { Moderately } & \text { Slightly } & \text { Slightly } & \text { Moderately } & \text { Strongly } \\ \text { Disagree } & \text { Disagree } & \text { Disagree } & \text { Agree } & \text { Agree } & \text { Agree }\end{array}$

1. I am satisfied with my ability to contribute to the clinical education process at this time.

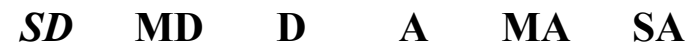

2. The implementation of the 2001 Proficiencies standards was a significant change to my practice.

3. The clinical education process is becoming more manageable.

4. The implementation of the 2001 clinical proficiencies was feasible.

5. The new 2001 standards have improved the clinical education process.

6. I have enough time to properly implement Learning Over Time

7. I am satisfied with my institution's contributions to the clinical education process (They understand and support).

8. The important factors affecting the clinical education process are within my control.

9. My program has clear expectations on programmatic teaching outcomes

$\begin{array}{llllll}1 & 2 & 3 & 4 & 5 & 6\end{array}$

$\begin{array}{llllll}1 & 2 & 3 & 4 & 5 & 6\end{array}$

$\begin{array}{llllll}1 & 2 & 3 & 4 & 5 & 6\end{array}$

$\begin{array}{llllll}1 & 2 & 3 & 4 & 5 & 6\end{array}$

$\begin{array}{llllll}1 & 2 & 3 & 4 & 5 & 6\end{array}$

$\begin{array}{llllll}1 & 2 & 3 & 4 & 5 & 6\end{array}$

$\begin{array}{llllll}1 & 2 & 3 & 4 & 5 & 6\end{array}$

$\begin{array}{llllll}1 & 2 & 3 & 4 & 5 & 6 \\ 1 & 2 & 3 & 4 & 5 & 6\end{array}$


Part Two: Factors that affect the delivery of clinical education. Please answer this section according to how these items affect you at this point in time. Circle the best answer.

Impedes Neutral Facilitates

$\begin{array}{lllllllll}\text { 10. My familiarity with the clinical } & -3 & -2 & -1 & 0 & 1 & 2 & 3 & \text { N/A }\end{array}$ education process

$\begin{array}{llllllllll}\text { 11. My familiarity with my program's } & -3 & -2 & -1 & 0 & 1 & 2 & 3 & \text { N/A }\end{array}$ clinical education process

$\begin{array}{llllllllll}\text { 12. Time allotted to me for my } & -3 & -2 & -1 & 0 & 1 & 2 & 3 & \text { N/A }\end{array}$ educational endeavors

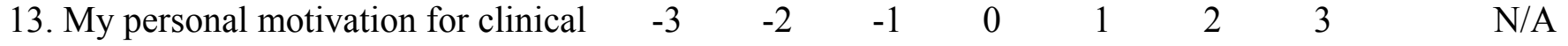
education

$\begin{array}{lllllllll}\text { 14. My teaching experience } & -3 & -2 & -1 & 0 & 1 & 2 & 3 & \text { N/A }\end{array}$

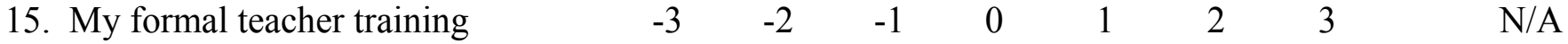

$\begin{array}{lllllllll}\text { 16. My current teaching confidence } & -3 & -2 & -1 & 0 & 1 & 2 & 3 & \text { N/A }\end{array}$

$\begin{array}{lllllllll}\text { 17. My job description } & -3 & -2 & -1 & 0 & 1 & 2 & 3 & \text { N/A }\end{array}$

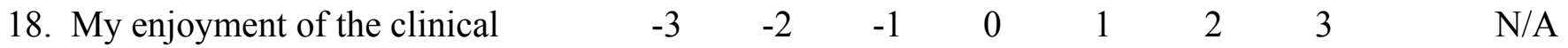
education process

$\begin{array}{lllllllll}\text { 19. Administrative support (support } & -3 & -2 & -1 & 0 & 1 & 2 & 3 & \text { N/A }\end{array}$ services such as clerical staff)

20. Department support (enough staff $\quad \begin{array}{lllllllll}-3 & -2 & -1 & 0 & 1 & 2 & 3 & \text { N/A }\end{array}$ ACIs)

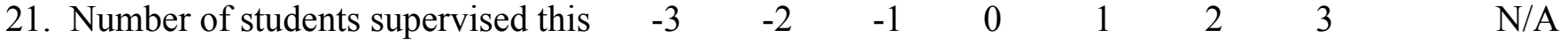
term 
22. Type of setting as it relates to

$$
-3
$$

$-3$

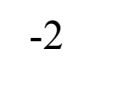

facility, practice, laboratory, game,

clinic, etc.)

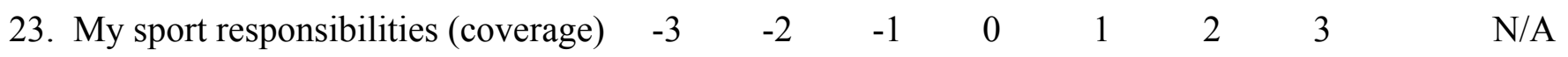

24. Type of sport

$\begin{array}{llllllll}-3 & -2 & -1 & 0 & 1 & 2 & 3 & \text { N/A }\end{array}$

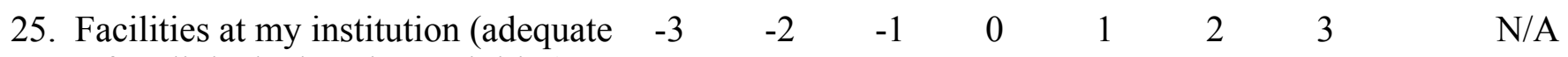
space for clinical education activities)

26. In general, my relationship with the $\quad \begin{array}{rllllllll} & -3 & -2 & -1 & 0 & 1 & 2 & 3 & \text { N/A }\end{array}$ students

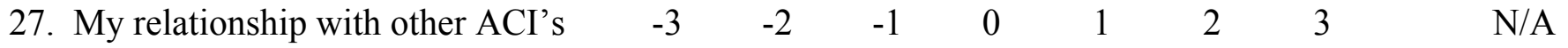

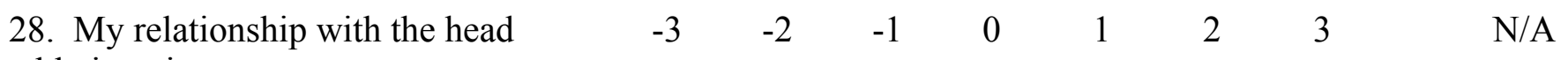
athletic trainer

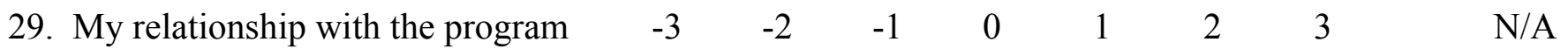
director

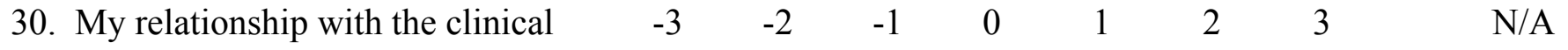
coordinator

$\begin{array}{llllllllll}\text { 31. My relationships with my } & -3 & -2 & -1 & 0 & 1 & 2 & 3 & \text { N/A }\end{array}$

supervisors outside the athletic training
department

$\begin{array}{llllllllll}\text { 32. Ease of documentation of the } & -3 & -2 & -1 & 0 & 1 & 2 & 3 & \text { N/A }\end{array}$

proficiencies

33. Ease documentation of learning over $\quad \begin{array}{lllllllll} & -2 & -1 & 0 & 1 & 2 & 3 & \text { N/A }\end{array}$ time

$\begin{array}{llllllllll}\text { 34. Satisfaction with job } & -3 & -2 & -1 & 0 & 1 & 2 & 3 & \text { N/A }\end{array}$

$\begin{array}{lllllllll}\text { 35. Administrative support with clinical } & -3 & -2 & -1 & 0 & 1 & 2 & 3 & \text { N/A }\end{array}$

education continuing education needs.

$\begin{array}{llllllllll}\text { 36. My leadership skills } & -3 & -2 & -1 & 0 & 1 & 2 & 3 & \text { N/A }\end{array}$

$\begin{array}{llllllllll}\text { 37. Coordination between classroom } & -3 & -2 & -1 & 0 & 1 & 2 & 3 & \text { N/A }\end{array}$ and clinical education (as it applies to my situation) 
$\begin{array}{llllllllll}\text { 38. Time allotted for my clinical } & -3 & -2 & -1 & 0 & 1 & 2 & 3 & \text { N/A }\end{array}$ education administration responsibilities

39. Support from my peers/colleagues $\quad \begin{array}{rllllllll}-3 & -2 & -1 & 0 & 1 & 2 & 3 & \text { N/A }\end{array}$

$\begin{array}{lllllllll}\text { 40. Acknowledgement and appreciation } & -3 & -2 & -1 & 0 & 1 & 2 & 3 & \text { N/A }\end{array}$ of my contributions to the clinical education process

Part Three: Needs assessment in clinical education

41. Of the factors listed above (10-40), which 5 would be most beneficial to address for improvement of the clinical education process to occur? Please list the corresponding number. Please note that the order of the selections is not important.

PART FOUR: Please tell us a bit about who filled out this survey.

42. Age:

43. Gender: Male Female

44. Race: African American

Asian American Caucasian Hispanic American Other

45. Highest Degree Completed: BA/BS MA/MEd/MS (specify):

$\mathrm{EdD} / \mathrm{PhD} /$ PsyD Other Degree 
46. How many years have you been a clinical instructor including years as an ACI?

47. Primary clinical education setting: Division I Division II Division III

Off site (specify):

Other (specify):

48. How many students are you currently directly responsible for regarding supervision?

49. How many hours per week, do you average engaged in clinical education related tasks?

50. What percent of your time is allocated to your clinical education job responsibilities in your job description?

51. Have you had any formal clinical education training other than the ACI course?

Yes No

52. What is your official position at your institution? (e.g. program director, staff, clinical coordinator, etc)

53. Do you believe that this is an important topic for athletic training research?

Yes No

Thank you for your valuable time.

Please feel free to add any additional comments in the space provided. 
Appendix G

Final Survey (paper form)

Part One: This section contains questions regarding your feelings of the clinical education process at this time. Please circle the best answer that most appropriately describes your current attitudes.

$\begin{array}{cccccc}\text { SD } & \text { MD } & \text { D } & \text { A } & \text { MA } & \text { SA } \\ 1 & 2 & 3 & 4 & 5 & 6 \\ \text { Strongly } & \text { Moderately } & \text { Slightly } & \text { Slightly } & \text { Moderately } & \text { Strongly } \\ \text { Disagree } & \text { Disagree } & \text { Disagree } & \text { Agree } & \text { Agree } & \text { Agree }\end{array}$

1. I am satisfied with my ability to contribute to the clinical education process at this time.

2. The implementation of the 2001 Proficiencies standards was a significant change to my practice.

3. The clinical education process is becoming more manageable.

4. The implementation of the 2001 clinical proficiencies was feasible.

5. The new 2001 standards have improved the clinical education process.

6. I have enough time to properly implement Learning Over Time.

7. I am satisfied with my institution's contributions to the clinical education process (They understand and support).

8. The important factors affecting the clinical education process are within my control.

9. My program has clear expectations on programmatic teaching outcomes

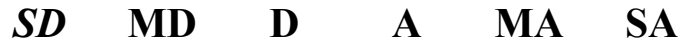

$\begin{array}{llllll}1 & 2 & 3 & 4 & 5 & 6\end{array}$

$\begin{array}{llllll}1 & 2 & 3 & 4 & 5 & 6\end{array}$

$\begin{array}{llllll}1 & 2 & 3 & 4 & 5 & 6\end{array}$

$\begin{array}{llllll}1 & 2 & 3 & 4 & 5 & 6\end{array}$

$\begin{array}{llllll}1 & 2 & 3 & 4 & 5 & 6\end{array}$

$\begin{array}{llllll}1 & 2 & 3 & 4 & 5 & 6\end{array}$

$\begin{array}{llllll}1 & 2 & 3 & 4 & 5 & 6\end{array}$

$\begin{array}{llllll}1 & 2 & 3 & 4 & 5 & 6\end{array}$

$\begin{array}{llllll}1 & 2 & 3 & 4 & 5 & 6\end{array}$


Part Two: Factors that affect the delivery of clinical education. Please answer this section according to how these items affect you at this point in time. Circle the best answer.

Impedes Neutral Facilitates

$\begin{array}{lllllllll}\text { 10. My familiarity with the clinical } & -3 & -2 & -1 & 0 & 1 & 2 & 3 & \text { N/A }\end{array}$ education process

$\begin{array}{llllllllll}\text { 11. My familiarity with my program's } & -3 & -2 & -1 & 0 & 1 & 2 & 3 & \text { N/A }\end{array}$ clinical education process

$\begin{array}{llllllllll}\text { 12. Time allotted to me for my } & -3 & -2 & -1 & 0 & 1 & 2 & 3 & \text { N/A }\end{array}$ educational endeavors

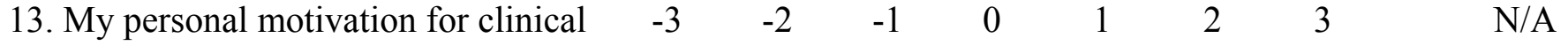
education

$\begin{array}{lllllllll}\text { 14. My teaching experience } & -3 & -2 & -1 & 0 & 1 & 2 & 3 & \text { N/A }\end{array}$

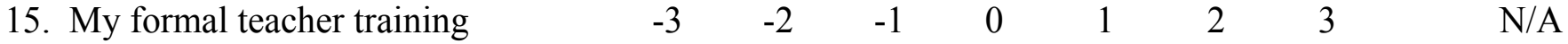

$\begin{array}{lllllllll}\text { 16. My current teaching confidence } & -3 & -2 & -1 & 0 & 1 & 2 & 3 & \text { N/A }\end{array}$

$\begin{array}{lllllllll}\text { 17. My job description } & -3 & -2 & -1 & 0 & 1 & 2 & 3 & \text { N/A }\end{array}$

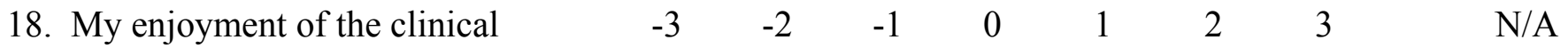
education process

$\begin{array}{lllllllll}\text { 19. Administrative support (support } & -3 & -2 & -1 & 0 & 1 & 2 & 3 & \text { N/A }\end{array}$ services such as clerical staff)

20. Department support (enough staff $\quad \begin{array}{lllllllll}-3 & -2 & -1 & 0 & 1 & 2 & 3 & \text { N/A }\end{array}$ ACIs)

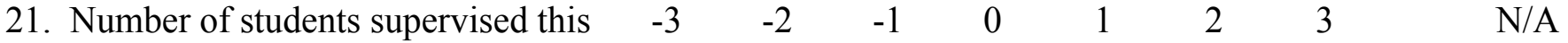
term 
22. Type of setting as it relates to

$$
-3
$$

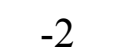

functionality (ex. Athletic training

facility, practice, laboratory, game,

clinic, etc.)

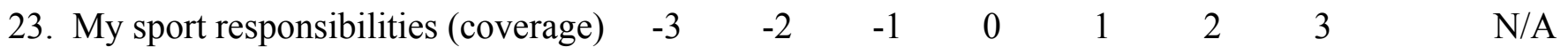

24. Type of sport

$\begin{array}{lllllll}-3 & -2 & -1 & 0 & 1 & 2 & 3\end{array}$

$\mathrm{N} / \mathrm{A}$

25. Facilities at my institution (adequate $\quad \begin{array}{llllllll}-3 & -2 & -1 & 0 & 1 & 2 & 3\end{array}$

N/A space for clinical education activities)

26. In general, my relationship with the $\quad \begin{array}{lllllllll} & -2 & -2 & -1 & 0 & 1 & 2 & 3 & \text { N/A }\end{array}$ students

27. My relationship with the other

ACI's

$\begin{array}{llllllll}-3 & -2 & -1 & 0 & 1 & 2 & 3 & \text { N/A }\end{array}$

28. My relationship with the head

$\begin{array}{lllllll}-3 & -2 & -1 & 0 & 1 & 2 & 3\end{array}$

N/A athletic trainer

29. My relationship with the program

$-3 \quad-2$

director

30. My relationship with the clinical coordinator

31. My relationships with my supervisors outside the athletic training department

32. Ease of documentation of the

$\begin{array}{lll}-3 & -2 & -1\end{array}$

$\begin{array}{lll}-3 & -2 & -1\end{array}$

0

$\begin{array}{lll}-3 & -2 & -1\end{array}$

$\begin{array}{llll}0 & 1 & 2 & 3\end{array}$

N/A proficiencies

33. Ease documentation of learning over time

34. Satisfaction with my job

$-3 \quad-2$

35. Institutional support with clinical education continuing education needs.

$\begin{array}{llllllll}-3 & -2 & -1 & 0 & 1 & 2 & 3 & \text { N/A }\end{array}$

36. My leadership skills

$-3 \quad-2 \quad-1$


37. Coordination between classroom and clinical education (as it applies to my situation)

38. Time allotted for my clinical education administration responsibilities

39. Support from my peers/colleagues

40. Acknowledgement and appreciation of my contributions to the clinical education process

$$
\begin{array}{lllllll}
-3 & -2 & -1 & 0 & 1 & 2 & 3
\end{array}
$$

Part Three: Needs assessment in clinical education

41. Of the factors listed above (10-40), which 5 would be most beneficial to address for improvement of the clinical education process to occur? Please list the corresponding number. Please note that the order of the selections is not important.

PART FOUR: Please tell us a bit about who filled out this survey.

42. Age:

43. Gender: Male Female

44. Race: African American

Asian American

Caucasian

Hispanic American

Other

45. Highest Degree Completed: BA/BS

MA/MEd/MS

EdD/PhD/PsyD Other Degree

(specify): 
46. How many years have you been a clinical instructor including years as an ACI?

47. Primary clinical education setting: Division I Division II Division III

Off site (specify):

Other (specify):

48. Currently, how many students are you directly responsible for regarding supervision?

49. On average, how many hours per week, do you spend engaged in clinical education related tasks?

50. What percent of your time, as listed in your job description is allocated to your clinical education job responsibilities?

51. Have you had any formal clinical education training other than the ACI course?

Yes No

52. What is your official position at your institution? (e.g. program director, staff, clinical coordinator, etc)

53. Do you believe that this is an important topic for athletic training research?

Yes No

Thank you for your valuable time.

Please feel free to add any additional comments in the space provided. 


\section{Appendix $\mathrm{H}$}

\section{$\underline{\text { Survey of Athletic Training Clinical Education }}$}

Part 1: This section contains questions regarding your feelings of the clinical education process at this time. Please select the best answer that most appropriately describes your current attitudes.

\begin{tabular}{|c|c|c|c|c|c|}
\hline SD & MD & D & A & MA & SA \\
\hline Strongly & Moderately & Slightly & Slightly & Moderately & Strongly \\
\hline Disagree & Disagree & Disagree & Agree & Agree & Agree \\
\hline
\end{tabular}

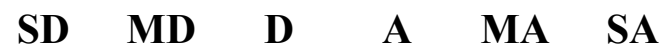

1. I am satisfied with my ability to contribute to

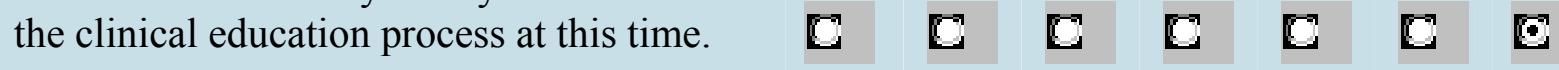

2. The implementation of the 2001

Proficiencies standards was a significant change to my practice.

\begin{tabular}{lllllll}
\hline & $C$ & $\mathbb{C}$ & $\mathbb{C}$ & $\mathrm{C}$ & $\mathrm{C}$ & $\mathbf{E}$
\end{tabular}

3. The clinical education process is becoming more manageable.

$\begin{array}{lllllll}C & \mathbb{C} & \mathbb{C} & \mathbb{C} & \mathbb{C} & \mathbb{C} & \mathbb{C}\end{array}$

4. The implementation of the 2001 clinical Proficiencies was feasible.

C E E E E E E

5. The new 2001 standards have improved the
clinical education process.

6. I have enough time to properly implement Learning Over Time.

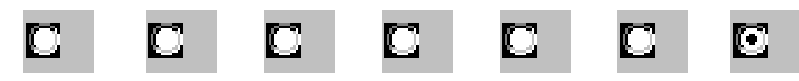

7. I am satisfied with my institution's contributions to the clinical education process (They understand and support). 


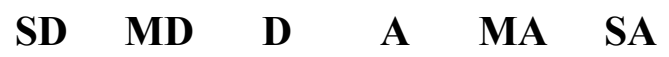

8. The important factors affecting the clinical education process are within my control.

\section{$\begin{array}{lllllll}\text { C } & \mathrm{C} & \mathrm{C} & \mathrm{C} & \mathrm{C} & \mathrm{C} & \mathbf{C}\end{array}$}

9. My program has clear expectations for teaching outcomes in clinical education.

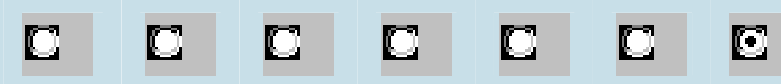

Part 2: Factors that affect the delivery of clinical education. Please answer this section according to how these items affect you at this point in time. Select the best answer. (Neutral= no effect; $\mathrm{N} / \mathrm{A}=$ not applicable to you at this time.)

\begin{tabular}{|c|c|c|c|c|c|c|c|c|c|}
\hline & & & & Neu & & & edes & & \\
\hline & Facil & ates & & & & & & & \\
\hline $\begin{array}{l}\text { 10. My familiarity with the clinical } \\
\text { education process }\end{array}$ & C & C & C & C & C & C & C & $\begin{array}{l}\mathbf{C} \\
\mathrm{N} / \mathrm{A}\end{array}$ & C \\
\hline $\begin{array}{l}\text { 11. My familiarity with my } \\
\text { program's clinical education process }\end{array}$ & C & C & C & C & C & C & $\mathbb{C}$ & $\begin{array}{l}\text { C } \\
\text { N/A }\end{array}$ & $\mathbb{C}$ \\
\hline $\begin{array}{l}\text { 12. Time allotted to me for my } \\
\text { educational endeavors }\end{array}$ & C & C & C & C & C & C & C & $\begin{array}{l}\mathbb{C} \\
\text { N/A }\end{array}$ & $\mathbb{C}$ \\
\hline $\begin{array}{l}\text { 13. My personal motivation for } \\
\text { clinical education }\end{array}$ & C & C & C & C & C & C & C & $\begin{array}{l}\text { C } \\
\text { N/A }\end{array}$ & C \\
\hline 14. My teaching experience & C & C & C & C & C & C & $\mathbb{C}$ & $\begin{array}{l}\mathrm{C} \\
\mathrm{N} / \mathrm{A}\end{array}$ & $\mathbb{C}$ \\
\hline 15. My formal teacher training & C & C & C & C & C & C & C & $\begin{array}{l}\mathbf{C} \\
\mathrm{N} / \mathrm{A}\end{array}$ & C \\
\hline 16. My current teaching confidence & C & C & C & C & C & C & C & $\begin{array}{l}\text { C } \\
\text { N/A }\end{array}$ & $\mathbb{C}$ \\
\hline 17. My job description & $\mathrm{C}$ & C & C & C & C & C & C & $\begin{array}{l}\text { C } \\
\text { N/A }\end{array}$ & $\mathbb{C}$ \\
\hline & Facil & tes & & Neu & & & edes & & \\
\hline
\end{tabular}




$\begin{array}{llllllllll}\begin{array}{l}\text { 18. My enjoyment of the clinical } \\ \text { education process }\end{array} & \mathbf{C} & \mathbf{C} & \mathbf{C} & \mathbf{C} & \mathbf{C} & \mathbf{C} & \mathbf{C} & \mathbf{C} & \mathbf{C} \\ \begin{array}{l}\text { 19. Administrative support (support } \\ \text { services such as clerical staff) }\end{array} & \mathbb{C} & \mathbf{C} & \mathbf{C} & \mathbf{C} & \mathbf{C} & \mathbf{C} & \mathbf{C} & \mathbf{C} & \mathbf{C} \\ \begin{array}{l}\text { 20. Department support (enough } \\ \text { staff ACIs) }\end{array} & \mathbb{C} & \mathbf{C} & \mathbf{C} & \mathbf{C} & \mathbf{C} & \mathbf{C} & \mathbf{C} & \mathbf{C} & \mathbf{C} \\ \begin{array}{l}\text { 21. Number of students supervised } \\ \text { this term }\end{array} & \mathbb{C} & \mathbf{C} & \mathbf{C} & \mathbf{C} & \mathbf{C} & \mathbf{C} & \mathbf{C} & \mathbf{C} & \mathbb{C} \\ \end{array}$
22. Type of setting as it relates to functionality (ex. Athletic training facility, practice, laboratory, game, clinic, etc.)

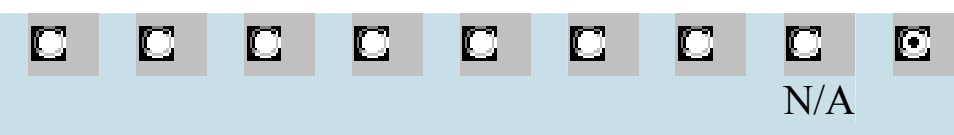

Facilitates

Neutral Impedes

23. My sport responsibilities (coverage)

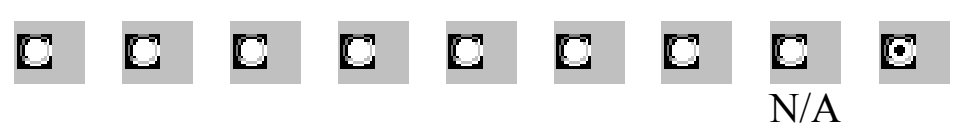

24. Type of sport

$\begin{array}{lllllllll}\mathbb{C} & \mathbb{C} & \mathbb{C} & \mathbb{C} & \mathbb{C} & \mathbb{C} & \mathbb{C} & \mathbb{C} & \mathbb{C}\end{array}$

25. Facilities at my institution (adequate space for clinical education activities)

$\begin{array}{lllllllll}\mathbf{C} & \mathbb{C} & \mathbb{C} & \mathbb{C} & \mathbb{C} & \mathbb{C} & \mathbb{C} & \mathbb{\mathrm { N }} & \mathbb{E}\end{array}$ $\begin{aligned} & \text { 26. In general, my relationship with } \\ & \text { the students }\end{aligned}$
$\begin{aligned} & \text { 27. My relationship with the other } \\ & \text { ACI's }\end{aligned}$ $\begin{array}{llllllllll}\text { 28. My relationship with the head } & \mathbf{C} & \mathbf{C} & \mathbf{C} & \mathbf{C} & \mathbf{C} & \mathbf{C} & \mathbf{C} & \mathbf{C} & \mathbf{C} \\ \text { athletic trainer } & \end{array}$ 
$\begin{array}{llllllllll}\begin{array}{l}\text { 30. My relationship with the clinical } \\ \text { coordinator }\end{array} & \boldsymbol{C} & \boldsymbol{C} & \boldsymbol{C} & \boldsymbol{C} & \boldsymbol{C} & \boldsymbol{C} & \boldsymbol{C} & \boldsymbol{C} & \boldsymbol{C} \\ \mathrm{N} / \mathrm{A} & \end{array}$ Neutral Impedes

Facilitates

31. My relationships with my supervisors outside the athletic training department

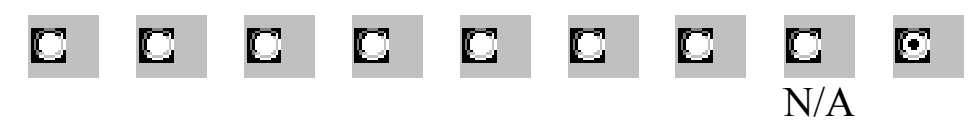
32. Ease of documentation of the Proficiencies
$\begin{array}{lllllllll}\mathbf{C} & \mathbf{C} & \mathbf{C} & \mathbb{C} & \mathbb{C} & \mathbf{C} & \mathbb{C} & \mathbb{C} & \mathbb{C}\end{array}$
33. Ease documentation of learning over time
$\begin{array}{llllllllll}\text { C } & \mathbf{C} & \mathbf{C} & \mathbf{C} & \mathbf{E} & \mathbf{E} & \mathbf{E} & \mathbf{E} & \mathbf{E}\end{array}$
\begin{tabular}{llllllllll} 
34. Satisfaction with my job & $\mathbf{C}$ & $\mathbf{C}$ & $\mathbf{C}$ & $\mathbf{C}$ & $\mathbf{C}$ & $\mathbf{C}$ & $\mathbf{C}$ & $\mathbf{C}$ & $\mathbf{C}$ \\
$\begin{array}{l}\text { 35. Institutional support with clinical } \\
\text { education continuing education }\end{array}$ & $\mathbb{C}$ & $\mathbf{C}$ & $\mathbf{C}$ & $\mathbf{C}$ & $\mathbf{C}$ & $\mathbf{C}$ & $\mathbf{C}$ & $\mathbf{C}$ & $\mathbf{C}$ \\
\hline
\end{tabular} needs.

$\begin{array}{llllllllll}\text { 36. My leadership skills } & \mathbf{C} & \mathbf{C} & \mathbf{C} & \mathbf{C} & \mathbf{C} & \mathbf{C} & \mathbf{C} & \mathbf{C} & \mathbf{C} \\ \begin{array}{l}\text { 37. Coordination between classroom } \\ \text { and clinical education (as it applies to }\end{array} & \mathbf{C} & \mathbf{C} & \mathbf{C} & \mathbf{C} & \mathbf{C} & \mathbf{C} & \mathbf{C} & \mathbf{C} & \mathbf{C} \\ \text { N/A }\end{array}$ my situation)

$\begin{array}{lllllllllll}\text { 38. Time allotted for my clinical } & & \mathbf{C} & \boldsymbol{C} & \boldsymbol{C} & \boldsymbol{C} & \boldsymbol{C} & \boldsymbol{C} & \boldsymbol{C} & \mathbf{C} & \mathbf{C} \\ \text { education administration } & & & & & & & & & \text { N/A } & \end{array}$ responsibilities

Facilitates

Neutral Impedes

39. Support from my peers/colleagues

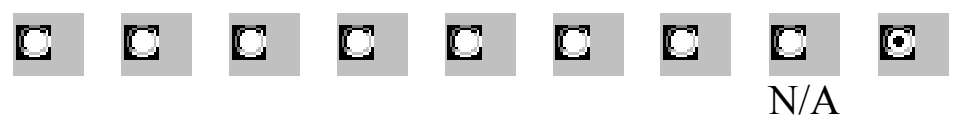

40. Acknowledgement and appreciation of my contributions to the clinical education process

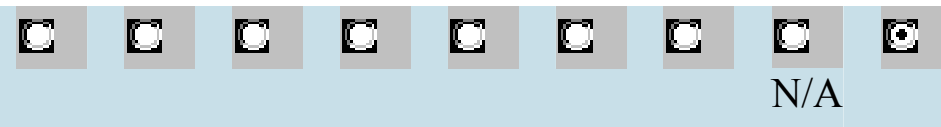


Part 3: Needs assessment in clinical education

41. Of the factors listed above (10-40), which 5 would be most beneficial to address for improvement of the clinical education process to occur? Please list the corresponding number. Please note that the order of the selections is not important.

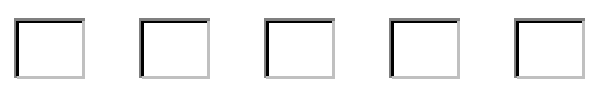

PART 4: Please tell us a bit about who filled out this survey.

42. Age:

43. Gender: $\mathbb{C}$ Male $\mathbb{C}$ Female $\mathbb{C}$

44. Race: $\mathbb{C}$ African American $\quad \mathbb{C}$ Asian American $\quad \mathbb{C}$ Caucasian $\mathbb{C}$ Hispanic American $\mathbb{C}$ Other $\mathbb{C}$

45. Highest Degree Completed: $\square$ BA/BS $\square$ MA/MEd/MS $\square_{\text {EdD/PhD/PsyD }}$ Other Degree (specify):

46. How many years have you been a clinical instructor, including years as an ACI?

47. Primary clinical education setting: $\quad \mathbb{D}$ Division I $\quad \mathbb{D}$ Division II $\quad \mathbb{D}$ Division III

Off site (specify):

Other (specify):

48. Currently, how many students are you directly responsible for regarding supervision?

49. On average, how many hours per week do you spend engaged in clinical education related tasks?

50. What percent of your time, as listed in your job description, is allocated to your clinical education job responsibilities?

51. Have you had any formal clinical education training other than the ACI course? 
$\mathbb{C}_{\text {Yes }} \mathbb{C}$

52. What is your official position at your institution? (e.g. program director, staff, clinical coordinator, etc)

53. Do you believe that this is an important topic for athletic training research?
C Yes
C No
(6)

54. Where did you hear of this survey?

$\mathbb{C}$ Program Director $\quad \mathbb{C}$ Athletic Training Education Listserv $\quad \mathbb{C}$ Other $\mathbb{C}$

Thank you for your valuable time.

Please feel free to add any additional comments in the space provided.

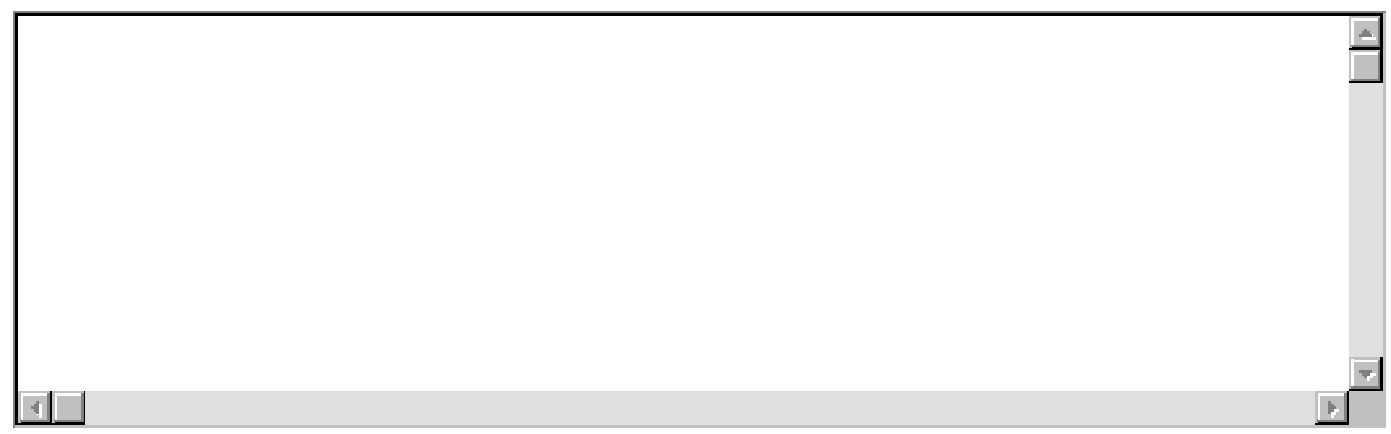


Table 1. Demographic Characteristics of ACIs

\begin{tabular}{llll}
\hline & $\mathrm{M}$ & $\mathrm{SD}$ & $\mathrm{R}$ \\
\hline Age & 35.6 & 8.37 & $23-62$ \\
CE duties (hrs/week) & 11.73 & 7.82 & $0-40$ \\
Years as CI & 7.34 & 6.37 & $1-30$ \\
Students directly supervised & 5.86 & 6.34 & $0-45$ \\
Contractual CE time & 18 & 19.28 & $0-80$ \\
\hline
\end{tabular}


Table 2. Other Demographic characteristics of ACIs

f $\%$

Sex

$\begin{array}{lcc}\text { Male } & 113 & 53.3 \\ \text { Female } & 97 & 45.8\end{array}$

Race

Caucasian

Hispanic

African American

Asian American

Degree

Master's

Doctorate

Bachelor's

Setting

Division I

Division III

Division II

NAIA

Other
96

6

3

1

151

37

20

76

61

41

17

17
35.8

28.8

2.8

1.4

.5

.2

71.2

17.5

9.4

19.3

.8

.8 
Table 2. Continued.

Important topic for AT research?

Yes

No

Additional CE training?

Yes

No

Where they heard about the survey?

Program director

105

78

27

128

AT listserve

Other
97.0

3.0

7

60.4

84

39.6

$\begin{array}{lr}05 & 97.0 \\ 7 & 3.0\end{array}$

39.6


Table 3. Title(s) Held By ACI's At Their Institution

\section{Titles of ACIs}

\begin{tabular}{|c|c|c|}
\hline \multicolumn{3}{|c|}{ Respondents $\quad(N=212)$} \\
\hline Program Director & 49 & 21.40 \\
\hline Clinical Coordinator & 32 & 13.97 \\
\hline Head Athletic Trainer & 31 & 13.54 \\
\hline Assistant Athletic Trainer & 27 & 11.79 \\
\hline Assistant Athletic Trainer, Instructor & 26 & 11.35 \\
\hline Staff ACI & 15 & 6.55 \\
\hline Graduate Assistant & 12 & 5.24 \\
\hline Athletic Trainer & 7 & 3.06 \\
\hline Department Chair, Program Director & 4 & 1.75 \\
\hline Program Director, Head Athletic Trainer & 3 & 1.31 \\
\hline Program Director, Clinical Coordinator & 2 & 0.87 \\
\hline Assistant Athletic Director, Sports Medicine & 1 & 0.44 \\
\hline Assistant Athletic Director, Head Athletic Trainer & 1 & 0.44 \\
\hline Physician's Assistant & 1 & 0.44 \\
\hline Assistant Program Director & 1 & 0.44 \\
\hline
\end{tabular}


Table 4. Perceptions of the Clinical Education Process since the Implementation of the 2001

Proficiencies

\begin{tabular}{llllll}
\hline Questions (1-9) & $N$ & $M$ & $S D$ & $R$
\end{tabular}

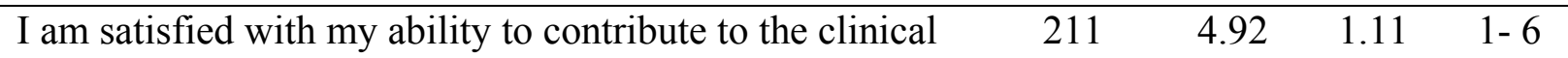
education process at this time.

I am satisfied with my institution's contributions to the $\quad \begin{array}{llll}210 & 4.50 & 1.21 & 1-6\end{array}$ clinical education process (They understand and support).

My program has clear expectations for teaching outcomes in $\begin{array}{lll}210 & 4.44 & 1.21\end{array} \quad \begin{aligned} & 1-6\end{aligned}$ clinical education.

The implementation of the 2001 Proficiencies standards was $\quad \begin{array}{llll}208 & 4.36 & 1.37 & 1-6\end{array}$ a significant change to my practice.

The new 2001 standards have improved the clinical $\quad 206 \quad 4.20 \quad 1.10 \quad 1-6$ education process.

The implementation of the 2001 clinical Proficiencies was $\quad 207 \quad 4.08 \quad 0.94 \quad 1-6$ feasible.

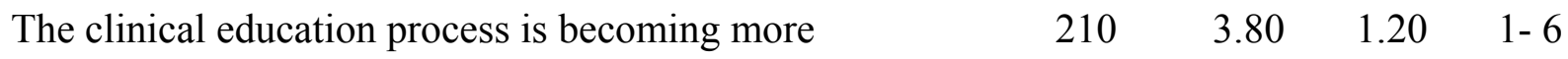
manageable.

The important factors affecting the clinical education $\quad \begin{array}{llll}209 & 3.78 & 1.28 & 1-6\end{array}$ process are within my control.

I have enough time to properly implement Learning Over $\quad \begin{array}{llll}210 & 3.70 & 1.35 & 1-6\end{array}$ Time.

Note. Questions were rated on a six-point scale from strongly disagree to strongly agree. 
Table 5. The Top Ten Most Facilitating Factors to the Clinical Education Process as Perceived by ACIs

\begin{tabular}{lllll}
\hline \multicolumn{1}{c}{ Questions } & $N$ & $M$ & $S D$ & $R$ \\
\hline In general, my relationship with the students (Q.26) & 212 & 2.35 & .72 & $0-3$ \\
My familiarity with my program's clinical education & 210 & 2.09 & 1.03 & $-2-3$ \\
$\quad$ process (Q.11) & & & & \\
My relationship with the other ACI's (Q.27) & 209 & 2.03 & 1.03 & $-2-3$ \\
My teaching experience (Q.14) & 208 & 2.02 & 1.09 & $-2-3$ \\
My familiarity with the clinical education process (Q.10) & 208 & 2.00 & 1.02 & $-3-3$ \\
My leadership skills (Q.36) & 209 & 1.98 & 0.87 & $-2-3$ \\
My relationship with the clinical coordinator (Q.30) & 159 & 1.97 & 1.43 & $-3-3$ \\
My current teaching confidence (Q.16) & 211 & 1.91 & 1.08 & $-2-3$ \\
My relationship with the head athletic trainer (Q.28) & 170 & 1.79 & 1.31 & $-3-3$ \\
$\begin{array}{l}\text { My personal motivation for clinical education (Q.13) } \\
\text { M }\end{array}$ & 212 & 1.77 & 1.30 & $-3-3$ \\
\hline
\end{tabular}

Note. Factors were scored on a seven-point scale from -3 (impedes) to +3 (facilitates) 
Table 6. Top Ten Least Facilitating Factors in the Clinical Education Process as Perceived by ACIs

$$
\text { Questions }
$$

Ease documentation of learning over time (Q.33)

Ease of documentation of the proficiencies (Q.32)

Time allotted for my clinical education administration responsibilities (Q.38)

Administrative support (support services such as clerical staff) (Q.19)

Time allotted to me for my educational endeavors (Q.12)

Department support (enough staff ACIs) (Q.20)

My job description (Q.17)

My sport responsibilities (coverage) (Q.23)

Institutional support with clinical education continuing education needs (Q.35)

Facilities at my institution (adequate space for clinical education activities) (Q25)

$\begin{array}{llll}N & M & S D & R\end{array}$

$\begin{array}{llll}205 & .07 & 1.86 & -3-3 \\ 208 & .16 & 1.85 & -3-3 \\ 206 & .21 & 1.88 & -3-3\end{array}$

$194 \quad .35 \quad 1.77 \quad-3-3$

$205 \quad .35 \quad 1.69 \quad-3-3$

$204 \quad .57 \quad 1.90 \quad-3-3$

$206 \quad .77 \quad 1.77 \quad-3-3$

$176 \quad .78 \quad 1.92 \quad-3-3$

$\begin{array}{llll}210 & .99 & 1.64 & -3-3\end{array}$

$212 \quad 1.07 \quad 1.82 \quad-3-3$

Note. Factors were scored on a seven point scale from -3 (impedes) to +3 (facilitates) 
Table 7. The Ten Most Important Factors to be First Addressed, As Selected By ACIs

\begin{tabular}{lll}
\hline \multicolumn{1}{c}{ Factors } & $f$ & $\%$ \\
\hline Ease of documentation of the proficiencies (Q.32) & 96 & 45.28 \\
Ease of documentation of learning over time (Q. 33) & 80 & 37.74 \\
Time allotted for my clinical education administration & 71 & 33.49 \\
$\quad$ responsibilities (Q.38) & 59 & 27.83 \\
Department support (enough staff ACIs) (Q.20) & 54 & 25.47 \\
Time allotted to me for my educational endeavors (Q.12) & 44 & 20.75 \\
My sport responsibilities (coverage) (Q.23) & 44 & 20.75 \\
Facilities at my institution (adequate space for clinical education & & 19.34 \\
activities) (Q.25) & 41 & 17.92 \\
Administrative support (support services such as clerical staff) & & \\
$\quad$ (Q.19) & 40 & 38 \\
Number of students supervised this term (Q.21) & & \\
Coordination between classroom and clinical education (as it applies \\
to my situation) (Q.37)
\end{tabular}

Note. Percentages represent the number of respondents out of the sample $(N=212)$ who selected the factors as important to be addressed. Percentages do not add to $100 \%$ since participants could select up to five items. 